\title{
III. Polen und die baltische Frage
}

\section{Die Randstaatenbündnispläne}

Die seit dem Jahre 1919 von Polen wiederholt unternommenen Versuche, einen Zusammenschluß aller Randstaaten Rußlands, d. h. ein Bündnis der drei baltischen Staaten Litauen, Lettland und Estland unter Einschluß Polens und Finnlands herbeizuführen, waren ergebnislos geblieben ${ }^{1}$. Obwohl allen Randstaaten das Ziel einer „Sicherung vor Rußland" gemeinsam war, hatte sich die Furcht vor dem Wiedererwachen des russischen Expansionsdranges nicht als eine genügend starke Tragfläche für ein Bündnis der Randstaaten untereinander erwiesen. Die Gründe lagen sowohl in der Verschiedenartigkeit der politischen Interessen der einzelnen Staaten als auch darin, daß der Grad einer etwaigen Bedrohung durch Sowjetrußland in den Randstaaten unterschiedlich stark empfunden wurde. Aufgrund dieser unterschiedlichen Interessenlage und insbesondere infolge des polnisch-litauischen Territorialkonfliktes um das Wilnagebiet ${ }^{2}$ zeichneten sich in der baltischen Politik nach Beendigung des polnisch-sowjetischen Krieges immer deutlicher zwei sich ausschließende Kombinationen zur Bildung eines Randstaatenbundes ab: eine „große Allianz“ "mit Beteiligung Polens, Finnlands, Estlands und Lettlands, in die nach den Plänen der polnischen Regierung später auch Litauen mit hineingezogen werden sollte ${ }^{3}$, oder aber ein „kleiner Randstaatenbund", bestehend aus den baltischen Republiken Litauen, Lettland und Estland.

\section{Lettlands Randstaatenpolitik zwischen Polen und Litauen}

Für die Verwirklichung der Idee eines keinen Randstaatenbundes setzte sich wegen des Wilnakonfliktes in erster Linie Litauen ein. Auf zunehmendes Interesse stieß dieses Projekt aber auch in Lettland. Bereits am 18. Januar 1921 sprach sich dort das Organ des lettischen Generalstabes, "Latvijas Kareivis", deutlich für ein Bündnis unter den drei baltischen Republiken aus und warf der polnischen Regierung zugleich ein unklares Verhältnis zu Lettland vor. Das Generalstabsorgan beklagte sich bitter darüber, daß Polen den lettischen Staat noch immer nicht de jure anerkannt habe und obendrein den Abschluß wirtschaftlicher Konventionen zwischen Lettland und Polen noch vor der De-jure-Anerkennung verlange. Außerdem kritisierte es die Tatsache, daß die polnische Regierung gegen die Aufnahme Lettlands und Estlands in den Völkerbund gestimmt hatte. „Die Polen“, kommentierte das Generalstabsorgan die Haltung Warschaus verärgert, „werden sich wieder auf die Großmächte Frankreich und England

1 Vgl. S. 24 und S. $53 \mathrm{ff}$.

2 Vgl. S. 34.

3 Ber. K. Nr. 235 und K. Nr. 240 v. Benndorf, Warschau, 15. III. bzw. 18. III. 1922, PA, IV Po, Pol 4, Bd. 1, Bl. 012, $038 \mathrm{f}$. 
berufen. Wenn das jedoch zutrifft, wenn Polen nicht mehr zwei oder drei Finger erheben darf, ohne die Genehmigung anderer einzuholen, dann ist es kein selbständiger Staat, sondern befindet sich im Verhältnis eines Vasallen seinen großen Gönnern gegenüber" ${ }^{\star 4}$.

Ursprünglich hatte der polnische Außenminister Sapieha Lettland die De-jure-Anerkennung im August 1920 angeboten, dieses Anerbieten allerdings mit der Bedingung verbunden, daß Lettland sich zum Abschluß eines gegen Sowjetrußland gerichteten Militärbündnisses mit Polen bereiterklären müßte. Diese Forderung wurde von der lettischen Regierung wegen der ungünstigen politischen und militärischen Lage Polens im Sommer 1920 zurückgewiesen ${ }^{5}$. Als die polnische Regierung Mitte November 1920 erneut erwog, die lettische Republik de jure anzuerkennen, nahm sie jedoch unter dem Druck der französischen Diplomatie von diesem Vorhaben wieder Abstand. $\mathrm{Zu}$ diesem Zeitpunkt galt in Paris eine Revision der Unabhängigkeit Lettlands und Estlands zugunsten eines nichtbolschewistischen Rußland noch als durchaus möglich ${ }^{6}$. Tatsächlich erfolgte dieser Schritt der polnischen Regierung erst, nachdem sich der Oberste Rat der Alliierten entschlossen hatte, Estland und Lettland mit Wirkung vom 26. Januar 1921 de jure anzuerkennen ${ }^{7}$.

Um den Eindruck zu verwischen, die polnische Regierung habe die alliierte Entscheidung erst abgewartet, bevor sie sich selbst zur Anerkennung Lettlands bereit fand, legte der polnische Vertreter in Riga, Witold Kamieniecki ${ }^{8}$, Mitte März 1921 der lettischen Regierung ein auf den 31. Dezember 1920 datiertes offizielles Dokument der polnischen Regierung vor, in dem die De-jure-Anerkennung durch Polen bereits ausgesprochen war. Durch eine verspätete Übermittlung, so erklärte Kamieniecki der lettischen Regierung, sei der Oberste Rat der bereits früher gefallenen Entscheidung der polnischen Regierung zuvorgekommen. Dieses zweifellos auf eine Instruktion aus Warschau zurückzuführende diplomatische Manöver wirkte in der Öffentlichkeit und Regierung Lettlands ausgesprochen lächerlich und führte eher zu einer Beeinträchtigung als zu einer Verbesserung der polnisch-lettischen Beziehungen ${ }^{9}$. Das in Lettland als Brüskierung und Verletzung des lettischen Nationalgefühls empfundene Verhalten der polnischen Regierung in der Anerkennungsfrage schien der Außenpolitik Lettlands die willkommene Gelegenheit zu bieten, sich von den polnischen Plänen in der

${ }^{4}$ Zit. nach Ber. K. Nr. 27 v. Wever, Riga, 20. I. 1921, PA, IV Rd, Lettland, Pol 1, Bd. 1. In ähnlicher Weise kritisierte auch der Leitartikel des christlich-nationalen „Latvijas Sargs“ (Nr. 8 v. 12. I. 1921) die polnische Politik gegenüber Lettland (zit. in Ber. K. Nr. 24 v. Wever, Riga, 14. I. 1921, PA, IV Rd, Pol 3, Lett/Lit, Bd. 1).

$s$ Andrzej Skrzypek, Zagadnienie polsko-łotewskiej konwencji wojskowej 1919-1925, in: Z dziejów 6 (1970), S. $223 \mathrm{f}$.

6 Andrzej Skrzypek, Związek baltycki, Warschau 1972, S. 80.

7 Ber. K. Nr. 40 v. Wever, Riga, 28. I. 1921, PA, IV Rd, Lettland, Pol 1, Bd. 1. Die De-jureAnerkennung Litauens verweigerte der Oberste Rat zu diesem Zeitpunkt mit der Begründung, die Grenzen Litauens seien noch nicht festgelegt (Senn, S. 60).

8 Vgl. Biographischer Anhang.

9 Rep. No. 582 v. Muller, Warschau, 23. XII. 1922, Poland. Annual Report, 1921, PRO, F. O. $371 / 9312 / \mathrm{N} 30 / 30 / 55$, S. 21, par. 110. 
Randstaatenfrage zu distanzieren. Wiederholt äußerte im Frühjahr 1921 der lettische Außenminister Meierovics ${ }^{10}$ seine wachsenden Bedenken gegen eine Beteiligung Polens an einem Randstaatenbündnis. Vor dem Kongreß des lettischen Bauernbundes hob er am 16. März 1921 nicht nur die Erfolge hervor, die der Friedensschluß mit Sowjetrußland bisher gebracht habe ${ }^{11}$, sondern betonte auch das gute Verhältnis Lettlands zu Estland und insbesondere zu Litauen. Dagegen verhindere das gespannte polnisch-litauische Verhältnis freundschaftliche Beziehungen zu Polen ${ }^{12}$.

Weit deutlicher wurde die Stellungnahme des lettischen Außenministers gegenüber Polen in einem Gespräch, das er einen Tag später mit dem deutschen Geschäftsträger in Riga, Wever, führte. Darin begründete Meierovics seinen Willen, in Zukunft eine Randstaatenpolitik ohne Polen zu betreiben mit dem Argument, „Lloyd George wünsche keine Freundschaft von Lettland mit Polen und ihm selbst sei eine Freundschaft mit Polen bei der Kampfstellung Polens gegen Rußland und gegen Deutschland zu gefährlich“"13. Meierovics” Bemerkungen über die Einstellung von Lloyd George gegenüber einem freundschaftlichen lettisch-polnischen Verhältnis waren zweifellos übertrieben, dennoch konnten seine Äußerungen als ein Hinweis auf Großbritanniens Mißtrauen gegen die in erster Linie gegen Rußland gerichteten Randstaatenpläne Polens verstanden werden.

Offenbar von der Vorstellung ausgehend, die baltischen Republiken gehörten wegen einer möglichen künftigen Wiedereingliederung in den russischen Staatsverband zur britischen Interessenphäre in Europa, hatte der polnische Außenminister Sapieha Ende Februar 1921 bei der Regierung in London anfragen lassen, ob ein Bündnis zwischen den baltischen Staaten und Polen die Billigung Großbritanniens finden würde. Das Außenministerium in London hatte daraufhin dem polnischen Außenminister eine ausweichende Antwort erteilt. Es sei ein Fehler zu glauben, betonte das Foreign Office, daß die britische Regierung irgendwelche politischen Interessen in diesem Gebiet beanspruche. Ihr sei zwar an einer gedeihlichen Fortentwicklung der jungen baltischen Republiken gelegen, die unmittelbaren britischen Interessen aber seien rein wirtschaftlicher Natur. Gleichzeitig allerdings - und dies zeigte unmißverständlich Lloyd Georges' Abneigung gegenüber den baltischen Plänen der polnischen Regierung - warnte das Foreign Office die polnische Regierung vor der Gefahr eines künftigen Konfliktes zwischen Polen und Sowjetrußland im Baltikum ${ }^{14}$.

$10 \mathrm{Vgl}$ : Biographischer Anhang.

11 Meierovics bezog diese Äußerungen in erster Linie auf die Entschädigungszahlungen, zu denen sich die Sowjetregierung aufgrund der vormaligen Zugehörigkeit des lettischen Staatsgebietes zum Russischen Reich im sowjetisch-lettischen Friedensvertrag vom 11. VIII. 1920 verpflichtet hatte. Nach Artikel XV sollte die Sowjetregierung zwei Monate nach der Ratifizierung des Friedensvertrages der lettischen Regierung 4 Millionen Goldrubel als Vorschuß auszahlen (DVP III, S. 113). Noch vor Ablauf dieser Frist - die Ratifikationsurkunden wurden am 4. Oktober 1920 in Moskau ausgetauscht - kam die Sowjetregierung Ende November 1920 dieser Verpflichtung nach (DVP IV, S. 644f.).

12 Ber. Ko 108 v. Wever, Riga, 16. III. 1921, PA, IV Rd, Lettland, Pol 1, Bd. 1.

13 Ber. Ko 113 v. Wever, Riga, 17. III. 1921, PA, IV Rd, Pol 3, Lett/Po, Bd. 1.

14 Rep. No. 582 v. Muller, Warschau, 23. XII. 1922, Poland. Annual Report, 1921, PRO, F. O. 
Den Absichtserklärungen Meierovics' folgten sehr bald konkrete Schritte. Als die lettische Regierung im Mai 1921 Litauen de jure anerkannte, tauchte in den anschlieBenden Besprechungen zwischen Meierovics und seinem litauischen Kollegen Purickis ${ }^{15}$ zum ersten Mal die Idee in deutlicher Form auf, das Projekt eines Randstaatenbundes etwas enger abzugrenzen und den Versuch zu machen, zunächst einmal eine Einigung unter den drei Staaten Litauen, Lettland und Estland herbeizuführen ${ }^{16}$. Insbesondere der lettischen Öffentlichkeit wurde eine schnelle Einigung über ein baltisches Bündnis in Aussicht gestellt. Charakteristisch für die Erwartungen, die die lettische Öffentlichkeit mit der Begegnung Purickis' mit Meierovics verband, waren die Kommentare der lettischen Presse. Unter der erwartungsvollen Überschrift „,Der Zusammenschluß des baltischen Dreibunds unmittelbar bevorstehend" faßte die deutschsprachige „Rigasche Rundschau“ in ihrer Ausgabe vom 7. Mai 1921 die lettischen Pressekommentare sowie eine Reihe von öffentlichen Erklärungen des litauischen und des lettischen Außenministers zusammen, in denen beide während ihrer Rigaer Besprechungen am 5. und 6. Mai 1921 den Gedanken einer Annäherung unter den drei baltischen Staaten besonders hervorhoben ${ }^{17}$. Von einem unmittelbar bevorstehenden Zusammenschluß der drei baltischen Staaten konnte ernsthaft aber keine Rede sein, da sich - von Estland einmal abgesehen - die Randstaatenkonzeptionen Litauens und Lettlands trotz der nach außen demonstrierten Einigkeit in dieser Frage in ihren Zielvorstellungen voneinander unterschieden. Während Meierovics in dem Projekt eines „,kleinen Randstaatenbundes“ den Kern eines Bündnisses sah, das später durch den Beitritt Polens und Finnlands erweitert werden sollte ${ }^{18}$, suchte die litauische Regierung mit ihren Bündnisplänen vor allem die Unterstützung und Rückendeckung ihrer baltischen Nachbarn in der Wilnafrage gegen Polen zu gewinnen. Aus diesem Grunde wollte sie einen Zusammenschluß der Randstaaten ausschließlich auf ein Dreierbündnis zwischen Litauen, Lettland und Estland begrenzt wissen. Einen Beitritt Polens zu diesem geplanten Bündnis zog Purickis allenfalls nach einer endgültigen Regelung der Wilnafrage in Erwägung ${ }^{19}$.

\section{Randstaatenbund und Wilnafrage}

Eine befriedigende Lösung des Wilnakonfliktes im Sinne der litauischen Regierung war zur Zeit der Verhandlungen zwischen Purickis und Meierovics in Riga in keiner

371/9312/N 30/30/55, S. 21, par. 111; E. W. Polson Newman, Britain and the Baltic, London 1930, S. 219.

15 Vgl. Biographischer Anhang.

16 Ber. Ko Nr. 157 und 161 v. Radowitz, Riga, 7. bzw. 11. V. 1921, PA, IV Rd, Pol 3, Lett/Lit, Bd. 1.

17 „Rigasche Rundschau“ Nr. 101 v. 7. V.1921, Anlage zu Ber. Ko Nr. 159 v. Radowitz, Riga, 10. V. 1921, ebenda.

18 Interview Meierovics' über den Randstaatenbund mit der schwedischsprachigen finnischen Tageszeitung „Hufvudstadsbladet“ Nr. 121 v. 5. V. 1921, Anlage zu Ber. v. Wallroth, Helsingfors, 10. V. 1921, PA, IV Nd, Pol 4, Geheimakten, Bd. 1.

19 Ber. Tgb. Nr. 1927 K. Nr. 182 v. Schönberg, Kowno, 22. III. 1921, PA, IV Rd, Pol 3, Lit/Po, Bd. 2 (II. Serie); Skrzypek, Związek bałtycki, S. 103, 105. 
Weise abzusehen, obwohl seit dem Frühjahr 1921 auf Anregung und unter Vermittlung des Völkerbundes ernsthafte Versuche unternommen wurden, die Streitfrage auf dem Verhandlungswege beizulegen. Im Mai 1921 begannen polnisch-litauische Verhandlungen über eine Beilegung des Wilnastreites in Brüssel. Sie wurden im Auftrage des Völkerbundes und unter dem Vorsitz des ehemaligen belgischen Außenministers Hymans geführt ${ }^{20}$.

Am 20. Mai legte Hymans einen 15-Punkte-Plan zur Lösung des polnisch-litauischen Konfliktes vor. Dieser sah im wesentlichen die gegenseitige Anerkennung der Unabhängigkeit und Souveränität sowie die Anknüpfung enger Beziehungen zwischen beiden Ländern vor. Polen und Litauen sollten ein militärisches Bündnis abschließen, zur Koordinierung und Uberwachung ihrer Außenpolitik eine gemeinsame außenpolitische Kommission bilden und weit über die Meistbegünstigungsklausel hinausgehende handelsvertragliche Vereinbarungen treffen. Polen sollte der freie Zugang zu den litauischen Häfen und freier Transitverkehr durch Litauen garantiert werden. Nach Schweizer Vorbild sollte sich Litauen als ein Bundesstaat aus zwei Kantonen - Kowno (Kaunas) und Wilna (Vilnius) - konstituieren, wobei die gemeinsame Hauptstadt Wilna sein sollte. Úber Unstimmigkeiten bei der Interpretation des Planes sollte ein vom Völkerbund zu benennender Schiedsrichter entscheiden ${ }^{21}$.

Trotz erheblicher kritischer Vorbehalte gegen einzelne Artikel des Hymans-Planes in der polnischen Publizistik, in der der Plan als ,antipolnisch“ angegriffen wurde ${ }^{22}$, akzeptierte Außenminister Skirmunt diese Vorschläge ,,im Prinzip“ am 15. Juli 1921. Gleichzeitig hielt jedoch die polnische Regierung alle Ansprüche auf das Wilnagebiet aufrecht ${ }^{23}$. Vom Vorsitzenden der litauischen Delegation, Galvanauskas, wurde der Plan am 22. Juli 1921 offiziell zurückgewiesen ${ }^{24}$. Die litauische Regierung stand bei dieser Entscheidung unter dem starken Druck der öffentlichen Meinung in Litauen, in der die Auffassung vorherrschte, der Plan ziele einerseits zwar auf einen Anschluß Wilnas an Litauen, andererseits aber auf eine Abtretung ganz Litauens an Polen ab. Ein am 3. September 1921 von Hymans vorgelegter, geringfügig modifzierter zweiter Plan - er sah als Konzession an Litauen die Autonomie Wilnas innerhalb des litauischen Staates mit eigener Lokalregierung vor, während alle übrigen Punkte unverändert blieben - wurde sodann sowohl von der polnischen als auch von der litauischen Regierung abgelehnt. Auch weitere von Hymans angeregte polnisch-litauische Verhandlungen und davon unabhängige Kontakte zwischen beiden Regierungen, die sich bis Anfang Dezember 1921 hinzogen, verliefen ergebnislos ${ }^{25}$.

${ }^{20}$ Societé des Nations, Journal Officiel IX (1921), Nr. 7, S. 170-178.

21 Text des Hymans-Planes: Exposé du Conflit lithuano-polonais. Deuxième assemblé de la Societé des Nations à Genève, Genf 1921, S. $94 \mathrm{f}$.

22 Vgl. Władysław Studnicki, Współczesne państwo litewskie i stosunek jego do Polaków, Warschau 1922, S. $102 \mathrm{f}$.

23 Exposé du Conflit lithuano-polonais, S. 18.

24 Societé des Nations, Journal Officiel X (1921), Nr. 28, S. 870 f.

${ }_{25} \mathrm{Zu}$ weiteren Einzelheiten des Hymans-Planes und zu den Reaktionen Polens und Litauens vgl. im übrigen ausführlich Senn, S. 66-82. Der gescheiterte Hymans-Plan blieb der einzige ernsthafte Versuch der gesamten Zwischenkriegszeit, den Wilnakonflikt mit friedlichen Mitteln beizulegen. 
Je stärker sich im Frühjahr und Sommer 1921 die Anzeichen für ein Scheitern der polnisch-litauischen Verhandlungen über die Wilnafrage mehrten, desto mißtrauischer wurden die zur gleichen Zeit geführten litauisch-lettischen Besprechungen über die Randstaatenfrage von der polnischen Presse verfolgt und als gegen die Interessen Polens gerichtet kommentiert. Innerhalb der polnischen Diplomatie befürchtete man sogar den Abschluß eines geheimen lettisch-litauischen Vertrages, eine - wie sich später herausstellte - allerdings unbegründete Sorge ${ }^{26}$.

In einem von fast der gesamten Rigaer Tagespresse wiedergegebenen Interview mit der lettischen Telegraphenagentur warnte der polnische Gesandte Kamieniecki bereits am 25. Mai 1921 eindringlich davor, das Zustandekommen eines Randstaatenbundes durch eine vorzeitige Beteiligung der litauischen Regierung zu gefährden. Er unterstrich bei dieser Gelegenheit den polnischen Standpunkt, daß ein engeres Bündnis zwischen Lettland, Litauen und Estland keine Garantie der staatlichen Unabhängigkeit dieser Länder bedeuten würde, sondern daß nur ein Randstaatenbund, dem auch Polen und Finnland angehörten, eine solche Garantie bieten könne. Eine Einbeziehung Litauens in einen Randstaatenbund aber müßte in jedem Falle solange als unzulässig betrachtet werden, als zwischen der polnischen und litauischen Regierung keine Einigung in der Wilnafrage erzielt worden $\operatorname{sei}^{27}$.

Mit seiner Politik der Annäherung an Litauen verfolgte indes Meierovics keineswegs das ihm von der polnischen Presse unterstellte Ziel, den litauischen Standpunkt in der Wilnafrage zu unterstützen und insofern einseitig für Litauen und gegen Polen Partei zu ergreifen. Dagegen hielt er aber einen Zusammenschluß der nördlichen Randstaaten ohne Litauen für unmöglich und beabsichtigte daher, einer von Polen betriebenen außenpolitischen Isolierung des litauischen Staates vorzubeugen. Eine Isolierung Litauens mußte seiner Meinung nach außerdem zu einer verstärkten Anlehnung des baltischen Nachbarn an Deutschland und an Sowjetrußland führen und insofern die außenpolitischen Interessen seines Landes berühren ${ }^{28}$. Meierovics' Befürchtungen waren in dieser Hinsicht nicht unbegründet. Sowohl das Deutsche Reich als auch Sowjetrußland unterhielten zu Litauen wesentlich bessere Beziehungen als vergleichsweise zu Lettland und Estland.

Zwischen Sowjetrußland und Litauen bestanden wenig Reibungspunkte, seitdem beide Länder infolge der Grenzregelung des polnisch-sowjetischen Friedensvertrages durch polnisches Territorium voneinander getrennt waren. Die Wilnafrage bildete sogar ein verbindendes Element in den Beziehungen beider Länder. In diesem Konflikt stand Sowjetrußland vorbehaltlos auf der Seite der litauischen Regierung und bemühte sich auf diese Weise um einen gemeinsamen Gegensatz zu Polen ${ }^{29}$. An einer Lösung des Wilnakonfliktes konnte der Sowjetregierung also nicht gelegen sein. Die

${ }^{26}$ Skrzypek, Związek bałtycki, S. 104.

27 Ber. Ko Nr. 171 v. Radowitz, Riga, 2. VI. 1921, PA, IV Rd, Pol 3, Lit/Po, Bd. 2 (II. Serie).

28 Chejno Arumjae, Za kulisami baltijskogo sojuza, Tallin 1966, S. $126 \mathrm{f}$.

29 Vgl. die Instruktion Čičerins an den sowjetischen Vertreter in Litauen, Aralov, vom 28. IV. 1921 (DVP IV, S. 84-88); Stanisław Łopatniuk, Stanowisko ZSRR wobec stosunków polsko-litewskich (1920-1928), in: Z dziejów 5 (1969), S. 60 ff. 
Beilegung des litauisch-polnischen Territorialkonfliktes mußte den empfindlichsten Punkt der baltischen Politik Polens beseitigen und somit letztlich die Möglichkeit zur Bildung eines Randstaatenbündnisses unter polnischer Führung fördern. Aus diesem Grunde verfolgte die Sowjetregierung die polnisch-litauischen Verhandlungen unter dem Vorsitz des Völkerbundes mit größtem Mißtrauen und bestärkte die litauische Regierung in ihrem W/iderstand gegen die Vorschläge Hymans ${ }^{30}$. Auch umgekehrt suchte die litauische Regierung die diplomatische Unterstützung durch die Sowjetregierung. Als Karachan in einer Unterredung mit dem deutschen Vertreter in Warschau betonte, die litauische Ablehnung der Hymans-Vorschläge sei auf eine russische Démarche in Kowno erfolgt ${ }^{31}$, fügte er mit der Bitte um strengste Vertraulichkeit hinzu: „Die diesbezügliche russische Note ist von der litauischen Regierung direkt erbeten worden; Litauen tut dies oft.“ Nach diesen Äußerungen zu schließen, kommentierte Schoen die vertraulichen Mitteilungen Karachans, ,wären die Beziehungen zwischen Kowno und Moskau ziemlich enge ${ }^{\text {"32 }}$.

Weit schwieriger gestalteten sich die Beziehungen zwischen Sowjetrußland und Lettland bzw. Estland. Im Zusammenhang mit angeblich von Moskau aus gesteuerten gewaltsamen Umsturzversuchen estnischer Kommunisten im Frühjahr 1921 kam es zu Spannungen zwischen Estland und Sowjetrußland ${ }^{33}$. Von zahlreichen Zwischenfällen war auch das sowjetisch-lettische Verhältnis gekennzeichnet. Das scharfe innenpolitische Vorgehen lettischer Regierungsbehörden gegen lettische Kommunisten trübte wiederholt die Beziehungen zur Sowjetregierung, ohne aber den Grad einer gefährlichen außenpolitischen Konfrontation zwischen beiden Staaten zu erreichen ${ }^{34}$.

30 Tel. Nr. 78 v. Schönberg, Kowno, 16. IX. 1921, PA, IV Rd, Pol 3, Lit/Po, Bd. 2 (I. Serie).

31 DVP IV, S. 331.

${ }^{32}$ Ber. K Nr. 782 v. Schoen, Warschau, 30. IX. 1921, PA, IV Rd, Pol 3, Lit/Po, Bd. 3 (II. Serie).

33 Am 4. April 1921 berichtete der deutsche Vertreter in Reval, er habe aus dem estnischen Außenministerium erfahren, daß estnische Kommunisten einen Umsturz in Estland für den 15. April 1921 geplant hätten. Die estnischen Regierungsbehörden hätten dagegen bereits umfassende Abwehrvorbereitungen getroffen. Dabei seien nach Aussagen estnischer Regierungsvertreter enge Verbindungen zwischen estnischen Kommunisten und russischen Agenten aufgedeckt worden, die erstere mit Geldmitteln und Waffen versorgt hätten (Tel. Nr. 51 v. Henkel, Reval, 4. IV. 1921, PA, IV Rd, Pol 3, Est/Ru, Geheimakten, Bd. 1). Die parteiamtliche Geschichte der Kommunistischen Partei Estlands spiegelt die Auseinandersetzungen zwischen den estnischen Kommunisten und den Regierungsbehörden Estlands in anderer Weise wider. Ohne Angaben darüber, ob konkrete Umsturzpläne der Kommunistischen Partei Estlands gegen die Regierung, geschweige denn konspirative Verbindungen zu sowjetischen Abgesandten bestanden oder nicht bestanden, spricht sie ganz allgemein von einem Aufschwung der revolutionären Bewegung der estnischen Arbeiterklasse im Frühjahr 1921. Mit dem Ziel ihrer Unterdrückung sei die estnische Bourgeoisie mit Terror und außergewöhnlichen Repressalien gegen die estnischen Kommunisten vorgegangen. In diesem Zusammenhang wird betont, daß in der Zeit von April bis Juli 1921 etwa 250 Arbeiter verhaftet worden seien (Očerki istorii Kommunističeskoj Partii Éstonii, Teil II [1920-1940] Tallin 1963, S. $58 \mathrm{f}$.$) .$

34 Von einer Verschärfung der lettisch-sowjetischen Beziehungen berichtete am 21. Juni 1921 ausführlich die deutsche Gesandtschaft in Riga. Diesem Bericht zufolge protestierte die Sowjetregierung mit einer am 11. Juni der lettischen Regierung überreichten Note scharf gegen die Aburteilung lettischer Kommunisten als einer Verletzung des lettisch-russischen Friedensvertrages. Nach 
Auch das Verhältnis Berlins zu Litauen war sehr viel unproblematischer als die Beziehungen des Reiches zu Lettland oder Estland. In einer im Randstaatenreferat des Auswärtigen Amtes abgefaßten Aufzeichnung vom 21. Juni 1921 hieß es ausdrücklich: „Litauen hat sich bisher als der deutschfreundlichste unter den baltischen Randstaaten erwiesen." Zwar habe es in der Zeit unmittelbar nach dem Bermont-Unternehmen ${ }^{35}$, von dem vor allem Lettland, aber auch Litauen betroffen war, nicht an Reibungen gefehlt, ,aber es ist stets gelungen, diese in verhältnismäßig kurzer Zeit beizulegen, wobei der gegenwärtige litauische Ministerpräsident Purickis, der vorher Gesandter in Berlin war, unzweifelhafte Verdienste hat". Es dürfte allerdings nicht übersehen werden, „daß in letzter Zeit, seitdem der polnisch-litauische Gegensatz in der Wilnafrage akute Formen angenommen hat, einzelne litauische Politiker bei der Entente Anlehnung suchen“36.

Eine mögliche Einigung Litauens mit Polen auf der Grundlage der Vorschläge Hymans war für die Reichsregierung in ähnlicher Weise unerwünscht wie für die Sowjetregierung. Auch sie fürchtete in erster Linie einen Machtzuwachs Polens und bemühte sich daher ebenfalls, die litauische Regierung zur Ablehnung des Hymans-Planes zu bewegen. „Betrachtet man die Frage vom Standpunkt der deutschen Interessen“, begründete der deutsche Gesandte in Kowno, Schönberg, die ablehnende Haltung der Reichsregierung den Vorschlägen Hymans gegenüber, ,so wird davon auszugehen sein, daß eine Besetzung Litauens und damit die Umklammerung Ostpreußens durch Polen die für uns ungünstigste Entwicklung wäre. Jeder Weg, der geeignet wäre, sie

der Darstellung des deutschen Gesandtenberichtes waren 18 führende lettische Kommunisten von einem Kriegsgericht wegen Hochverrats zum Tode verurteilt worden. 10 Todesurteile seien in der Nacht vom 10. auf den 11. Juni vollstreckt worden, während die Strafen der übrigen 8 minderjährigen Verurteilten zu lebenslänglicher Zwangsarbeit umgewandelt wurden. Die Verurteilten hätten vor Gericht erklärt, daß sie aufgrund des lettisch-sowjetischen Friedensvertrages für Rußland zu optieren wünschten, was dem sowjetischen Gesandten Ganeckij bekannt geworden sei. Der Optionsvertrag zwischen Lettland und Rußland sei aber zu diesem Zeitpunkt - er wurde erst am 22. Juli 1921 abgeschlossen (DVP IV, S. 693) - noch nicht unterzeichnet gewesen, so daß nach Ansicht des lettischen Außenministeriums Ganeckij jede Grundlage für die Forderung nach Auslieferung der Verurteilten gefehlt habe (Ber. Ko 179 v. Radowitz, Riga, 21. VI. 1921, PA, IV Rd, Pol 3, Lett/Ru, Geheimakten, Bd 1).

$35 \mathrm{Zu}$ dem Bermont-Unternehmen vom Herbst 1919, das eine Kriegserklärung Lettlands an Deutschland veranlaßte, vgl. neben dessen eigener Darstellung: Fürst Awaloff (= Bermont), Im Kampf gegen den Bolschewismus, Glückstadt, Hamburg 1925 vor allem: Die Kämpfe im Baltikum nach der zweiten Einnahme von Riga. Darstellungen aus den Nachkriegsjahren deutscher Truppen und Freicorps, Bd. III, Berlin 1938. Außerdem die ausführliche, auch deutsch erschienene sowjetlettische Darstellung von V.Sipols, Die ausländische Intervention in Lettland 1918-1920, Berlin 1961, S. 158-178. Zu den schädlichen Auswirkungen des Bermont-Unternehmens auf die deutsch-litauischen Beziehungen vgl. den Bericht des Generalbevollmächtigten des Deutschen Reiches für Litauen, Zimmerle, vom 16. X. 1919, abgedruckt bei Marianne Bienhold, Die Entstehung des litauischen Staates in den Jahren 1918-1919 im Spiegel deutscher Akten, (phil. Diss.) Bochum 1976, Anhang, S. 1-9.

36 Unsignierte Aufzeichnung unter Journal-Nr. IV Rd 203 v. 21. VI. 1921: „Verhältnis Deutschlands zu den Randstaaten“, PA, IV Rd, Pol 2, Rd/Dt. 
aufzuhalten, würde vom deutschen Standpunkt aus den Vorzug verdienen“"37. Auch die zwischen Deutschland und Litauen strittige Memelfrage ${ }^{38}$ wurde von deutscher Seite vornehmlich unter dem Gesichtspunkt gemeinsamer deutsch-litauischer Interessen gegen Polen gesehen. Eine Auseinandersetzung mit Litauen in dieser Frage wurde daher von der Reichsregierung peinlichst vermieden ${ }^{39}$. Engste Beziehungen bestanden zwischen Litauen und Deutschland schließlich im wirtschaftlichen Bereich. In der erwähnten Aufzeichnung des Randstaatenreferats vom 21. VI. 1921 hieß es dazu lakonisch: „Im Wirtschaftsleben Litauens nimmt Deutschland unbestritten die erste Stelle ein" $" 40$.

Sah Meierovics in den guten Beziehungen Litauens zu Deutschland und Sowjetrußland eine Gefahr für die staatliche Unabhängigkeit der jungen baltischen Republiken, so mußte es durchaus in seinem Interesse liegen, Litauen durch die Einbeziehung in einen baltischen Staatenbund. deutschen und sowjetrussischen Einflüssen zu entziehen. Bestärkt wurde er in dieser Konzeption zweifellos auch durch die schwierigen Beziehungen seines eigenen Landes zu Deutschland. Die Erinnerungen an die Kriegszeit und an das folgende Bermont-Unternehmen ${ }^{41}$ waren in Lettland weit gegenwärtiger als in Litauen und belasteten das deutsch-lettische Verhältnis. Zwar stellte das deutsch-lettische Abkommen vom 15. Juli 1920 das beiderseitige Verhältnis infolge der darin enthaltenen Bestimmungen über freien Transit und gegenseitige Meistbegünstigung im Handelsverkehr auf eine neue Basis, dennoch erschwerte die Beziehungen weiterhin, daß Lettland die Reichsdeutschen einem Agrargesetz unterwarf, das faktisch einer entschädigungslosen Enteignung gleichkam ${ }^{42}$.

In einer ähnlichen außenpolitischen Lage gegenüber Sowjetrußland und Deutschland befand sich auch Estland. Neben den estnisch-russischen Spannungen wirkten die estnisch-deutschen Gegensätze, die vor allem auf die Anwendung des estnischen Agrargesetzes auch auf Reichsdeutsche sowie die estnische Valutaordnung zurückzu-

37 Ber. Tgb. Nr. KN 696 v. Schönberg, Kowno, 2. XI. 1921, PA, IV Rd, Pol 3, Lit/Po, Bd. 3 (II. Serie).

38 Das zwischen dem Reich und Litauen gelegene Memelland, aufgrund des Art. 99 des Versailler Vertrages vom Reich abgetrennt, unterstand seit dem 10. Januar 1920 alliierter Verwaltung. (Zu den Entscheidungen der Alliierten vgl. F. Janz, Die Entstehung des Memelgebietes, Berlin 1928). Die Reichsregierung setzte sich, da eine Wiederangliederung des Gebietes infolge des Versailler Vertrages ausgeschlossen war, für die Bildung eines unter alliierter Oberhoheit stehenden Freistaates mit eigener Autonomie ein (Aufzeichnung Dirksens v. 25. II. 1922, PA, Büro RM, Memel, Bd. 1). Die litauische Regierung erhob ihrerseits aus wirtschaftlichen und politischen Gründen Besitzansprüche auf das Memelland (vgl. E. A. Plieg, Das Memelland 1920-1939, Würzburg 1962, S. 16).

${ }^{39}$ Das Auswärtige Amt betonte nicht nur, daß „die Memelfrage die deutsch-litauischen Beziehungen nicht getrübt hat“, sondern stellte auch mit Befriedigung fest: „Die Franzosen als Verwalter des Memelgebietes haben es verstanden, die Unzufriedenheit der Litauer wegen der Entwicklung dieser Frage ausschließlich auf sich zu lenken“. Unsignierte Aufzeichnung unter Journal-Nr. IV Rd 203 v. 21. VI. 1921: „Verhältnis Deutschlands zu den Randstaaten“, PA, IV Rd, Pol 2, Rd/Dt.

40 Ebenda.

41 Vgl. Anm. 35.

42 Zum lettischen Agrargesetz vgl. S. 126, Anm. 121. 
führen waren ${ }^{43}$, als ein wichtiges Element der estnischen Außenpolitik, die Zusammenarbeit mit Lettland zu suchen. Insgesamt aber trug nach Auffassung des deutschen Gesandten in Riga, Radowitz, das Projekt eines Zusammenschlusses der drei baltischen Staaten Litauen, Lettland und Estland weniger eine Spitze gegen Deutschland als vielmehr gegen Rußland. Der Mangel an Vertrauen in die russische Politik und die Unsicherheit über die Entwicklung des mächtigen Nachbarn blieb ohne Zweifel die stärkste Triebfeder in diesen Bestrebungen ${ }^{44}$.

Die Randstaatenpläne Meierovics' stießen jedoch innerhalb der lettischen Regierung auf erhebliche Vorbehalte. Ministerpräsident Ulmanis ${ }^{45}$, der spätere Staatspräsident Čakste $^{46}$ sowie Teile der lettischen Sozialdemokratie erhoben Einwände, da sie aus einer zu starken Hinwendung Lettlands an Litauen eine weitere Belastung der Beziehungen zu Polen befürchteten ${ }^{47}$. Der erste Anlauf zur Bildung eines baltischen Dreibundes war damit vorerst gescheitert. Widersprüche unter den baltischen Staaten, ihre unterschiedlichen Beziehungen zu Polen wie zu Sowjetrußland, zum geringeren Teil auch zu Deutschland, wirkten hemmend auf die Bündnispläne.

\section{Estlands Randstaatenpolitik zwischen Finnland, Lettland und Polen}

Wesentlich kühler als Lettland stand von Anfang an Estland dem Gedanken eines kleinen Baltenbundes gegenüber. Als eine litauische Regierungsdelegation die estnische Regierung im März 1921 in dieser Frage sondierte, wurde ihr unmißverständlich erklärt, Estland werde an einer Einbeziehung Polens in einen baltischen Bund festhal$\operatorname{ten}^{48}$. In der Wilnafrage wahrte die estnische Regierung im übrigen einen strikt neutralen Standpunkt und unterhielt sowohl mit Litauen als auch mit Polen durchaus freundschaftliche Beziehungen ${ }^{49}$. Engste Beziehungen strebte die estnische Regierung zu Finnland und dem benachbarten Lettland an, in denen sie natürliche Verbündete gegen Sowjetrußland sah. Das wiederholte Drängen des bedeutenden estnischen Poli-

43 Der erwähnten Aufzeichnung des Randstaatenreferats v. 21. VI. 1921 zufolge seien Reichsdeutsche ohne Entschädigung ihres Grundbesitzes enteignet und gemäß der Valutaordnung deutsche Gläubiger erheblich geschädigt worden. Die estnischen Schuldner hätten die Forderungen, die in Reichsmark erhoben wurden, in Eesti-Mark lediglich zum Kurse von einer Eesti-Mark entsprechend einer Reichsmark bezahlt, was für die deutschen Gläubiger den Verlust von etwa $5 / 6$ ihrer Forderungen bedeutet hätte. Reklamationen der Reichsregierung gegen die Anwendung dieser Gesetzesvorschriften auf Reichsangehörige seien ohne greifbaren Erfolg geblieben. Andererseits hätte sich der Handelsverkehr, vor allem der Transitverkehr nach Rußland bisher in befriedigender Weise entwickelt, „obwohl eine vertragliche Regelung unserer wirtschaftlichen Beziehungen bisher nicht erfolgt ist".

44 Ber. Ko Nr. 161, Riga, 11. V. 1921, IV Rd, Pol 3, Lett/Lit, Bd. 1.

$45 \mathrm{Vgl}$. Biographischer Anhang.

46 Vgl. Biographischer Anhang.

47 Skrzypek, Związek baltycki, S. 104.

48 Ber. Tgb. Nr. 1447 K. Nr. 155 v. Schönberg, Kowno, 8. III. 1921, PA, IV Rd, Pol 3, Lit/Po, Bd. 2 (I. Serie).

49 Ber. Tgb. Nr. 7095 K. Nr. 551 v. Schönberg, Kowno, 5. IX. 1921, PA, IV Rd, Estland, Pol 1, Bd. 1. 
tikers und mehrfachen Ministerpräsidenten Jaan Tõnisson ${ }^{50}$ nach einem Militärbündnis mit Finnland traf jedoch auf eine noch unentschiedene außenpolitische Orientierung der finnischen Republik, die zwischen einer engeren Bindung an die skandinavischen Staaten oder aber einer Annäherung an Polen und die baltischen Republiken schwankte ${ }^{51}$.

Während sich der finnische Ministerpräsident Vennola und der Außenminister Hol$\mathrm{sti}^{\mathrm{52}}$, von den regierenden Zentrumsparteien des finnischen Reichstages - Agrarpartei und Fortschrittspartei - unterstützt, für eine Beteiligung Finnlands an einem Randstaatenbund unter Einschluß Polens und insbesondere auch für ein bilaterales militärisches Bündnis mit Estland einsetzten, opponierten dagegen die finnischen Sozialdemokraten und Sozialisten ebenso wie die finnischen Rechtsparteien. Die Letzteren, die Schwedische Volkspartei und die Partei der Nationalen Konsolidierung, vertraten eine entschieden skandinavische Orientierung und suchten Anlehnung an Schweden. An den Bestand selbständiger baltischer Republiken glaubten sie nicht, sondern hielten eine Wiedereingliederung Litauens, Lettlands und Estlands, nicht aber Finnlands in ein künftiges nichtbolschewistisches Rußland für eine reale Möglichkeit. In einer Verbindung mit den baltischen Staaten sahen sie für den Fall einer militärischen Auseinandersetzung mit Sowjetrußland außerdem kaum wertvolle militärische Hilfe $^{53}$. Ein bilaterales finnisch-polnisches Bündnis bedeutete dagegen ihrer Auffassung nach eine weitgehende militärische Sicherung gegen Sowjetrußland. Andererseits enthielte ein derartiges Bündnis aber wegen der Politik Polens gegenüber dem Deutschen Reich wiederum erhebliche Risiken und sei daher nicht annehmbar ${ }^{54}$. Bei den finnischen Linksparteien spielte die Rücksichtnahme auf die innerhalb der finnischen Arbeiterbewegung starken prokommunistischen und prosowjetischen Stimmungen die entscheidende Rolle, sich einer engeren gegen Sowjetrußland gerichteten Verbindung mit den baltischen Staaten und Polen zu widersetzen ${ }^{55}$. Da die finnische Regierung auf die Unterstützung entweder der Rechts- oder der Linksparteien angewiesen war, um ihre Entscheidungen mehrheitlich durchsetzen zu können, mußte sie das estnische Angebot vorerst ablehnen.

Aufgrund der Unentschiedenheit der außenpolitischen Orientierung Finnlands konzentrierte sich die estnische Außenpolitik unter Außenminister Piip ${ }^{56}$ zunächst stärker auf die Ausgestaltung der Beziehungen zu den benachbarten baltischen Randstaaten.

so Vgl. Biographischer Anhang.

51 Zum historischen Hintergrund der beiden außenpolitischen Richtungen vgl. Marjan Korczak Stosunek Finlandji do zagadnienia związku państw baltyckich, in: Przegląd Polityczny 1 (1925), S. 7f.

52 Vgl. Biographischer Anhang.

53 Ber. Nr. 552 v. Wallroth, Helsingfors, 20. VI. 1921, PA, IV Nd, Finnland, Pol 1, Bd. 1; vgl. Arumjaè, S. $108 \mathrm{ff}$.

54 Ber. Nr. 734 v. Wallroth, Helsingfors, 19. VIII. 1921, PA, IV Nd, Pol 3, Fi/Ru, Bd. 1 (II. Serie).

s5 Zur Haltung der finnischen Linksparteien zu dieser Zeit in Fragen der Innen- und Außenpolitik vgl. Gennadij A. Borovkov, Parlamentarizm i finskoe rabočee dviženie (1919-1923), in: Skandinavskij Sbornik 17 (1972), S. 129-148.

56 Vgl. Biographischer Anhang. 
In einer am 26. Mai 1921 vom Auswärtigen Ausschuß des estnischen Parlaments verabschiedeten Resolution, welche die Richtlinien der künftigen estnischen Randstaatenpolitik vorzeichnete, rangierte der Abschluß eines Verteidigungsbündnisses mit Lettland an erster Stelle. Diesem Abkommen sollte sich sodann Litauen anschließen können, wobei sichergestellt sein müsse, daß sich das Bündnis nicht gegen Polen richte. Ein bestehendes Dreierbündnis Estland - Lettland - Litauen sollte daraufhin den Anschluß Finnlands und Polens aktiv anstreben ${ }^{57}$.

Diese Konzeption der estnischen Regierung enthielt sowohl Elemente der polnischen wie der lettischen Randstaatenpläne. In der Zielvorstellung deckte sie sich insoweit mit den Absichten der polnischen Regierung, als sie eindeutig auf den Zusammenschluß aller fünf an einer Randstaatenkombination beteiligten Länder, also der baltischen Staaten einschließlich Finnlands und Polens, ausgerichtet war. In diesem Punkt widersprach das estnische Projekt auch nicht den Randstaatenplänen von Außenminister Meierovics. Was das estnische Konzept einer Randstaatenbündnispolitik allerdings von den polnischen Bestrebungen deutlich unterschied, war die vorrangige Einbeziehung Litauens in einen zunächst zu bildenden kleinen Bund. Gerade hierin stimmte indes der estnische Plan wiederum weitgehend mit der Randstaatenpolitik des lettischen Außenministers überein.

Lagen nunmehr die günstigsten Voraussetzungen für den Abschluß zweiseitiger lettisch-estnischer Vereinbarungen vor, so gewannen die Randstaatenpläne Meierovics' um so mehr an Bedeutung, als im Juni 1921 in Lettland das Kabinett Ulmanis zurücktrat. Außer der Leitung des lettischen Außenministeriums übernahm Meierovics am 19. VI. 1921 auch das Amt des Ministerpräsidenten und setzte nach der Regierungsneubildung seinen bisherigen außenpolitischen Kurs in der Randstaatenfrage mit Nachdruck, ohne nennenswerten Widerstand im Innern, fort ${ }^{58}$. Anfang Juli 1921 aufgenommene Verhandlungen zwischen Meierovics und Piip konnten bereits am 7. Juli 1921 in der estnischen Hauptstadt Reval mit der Unterzeichnung einer lettischestnischen Militärkonvention, eines Konsularabkommens und einer Post- und Telegraphenkonvention abgeschlossen werden ${ }^{59}$.

\section{Das Bündnisprojekt Estland - Lettland - Litauen und die Haltung Sowjetrußlands und Polens}

Unmittelbar nach Abschluß der lettisch-estnischen Verträge, die am 1. November 1923 zu einem regelrechten politisch-militärischen Bündnis ${ }^{60}$ ausgestaltet wurden und fortan als fester Kern und Ausgangspunkt aller Randstaatenkombinationen mehr und

57 Arumjaè, S. $118 \mathrm{f}$.

58 Skrzypek, Związek baltycki, S. 107.

59 Arumjaè, S. 120; Edgar Anderson, Latvia - Past and Present, o. O. 1968 (Ms), S. 127; Skrzypek, Zwiạzek bałtycki, S. 107 datiert die Unterzeichnung der lettisch-estnischen Verträge unrichtig auf den 11. Juli 1921 in der lettischen Hauptstadt Riga.

60 Wortlaut des Defensivbündnisses v. 1. XI. 1923, in: Société des Nations, Recueil des traités, Bd. 33, Genf 1924, S. 81 f.; deutsche Úbersetzung: Hoetzsch-Bertram, Dokumente zur Weltpolitik der Nachkriegszeit, H. 6, Leipzig, Berlin 1933, S. 43 ff. 
mehr an Bedeutung gewannen ${ }^{61}$, reiste Purickis nach Riga, um dort mit Meierovics und mit Piip, der ebenfalls in die lettische Hauptstadt gekommen war, die weiteren Schritte in der Frage eines Randstaatenbundes zu beraten. Während der dreitägigen Rigae: Verhandlungen (12. bis 14. Juli 1921) zwischen den Außenministern Estlands, Lettlands und Litauens stellte sich indes heraus, daß die Standpunkte der beteiligten Regierungen zu unterschiedlich waren, um den geplanten Zusammenschluß zu verwirklichen. Die litauische Regierung mußte ihre Hoffnungen, Lettland und Estland würden sich in der Wilnafrage mit ihr solidarisch erklären, enttäuscht aufgeben. Außerdem beharrten Lettland und insbesondere Estland mit Entschiedenheit darauf, daß ein anzustrebendes litauisch-lettisch-estnisches Dreierbündnis dem Beitritt Polens und Finnlands offengehalten werden müsse ${ }^{62}$. Unter diesen Umständen sah sich die litauische Regierung nicht in der Lage, einem engeren Zusammenschluß der drei baltischen Staaten zuzustimmen. Das Ergebnis der Rigaer Besprechungen beschränkte sich daher lediglich auf die Unterzeichnung einer Post- und Telegraphenkonvention, eines Konsularabkommens, eines Auslieferungsvertrages und einer Einigung über die zwischenstaatlichen Rechtsverhältnisse der Staatsbürger ${ }^{63}$. Um einer möglichen Belastung der estnisch-polnischen Beziehungen vorzubeugen, ließ die estnische Regierung noch während der laufenden Verhandlungen in Riga mehrfach gegenüber polnischen Regierungsvertretern erklären, Estland werde sich an keinem in irgendeiner Weise gegen Polen gerichteten Bündnis beteiligen ${ }^{64}$.

Die Sowjetregierung verfolgte die Entwicklung mit großer Aufmerksamkeit. Sie versuchte nicht etwa die Ansätze zur Bildung eines kleinen Randstaatenbundes ohne Teilnahme Polen und Finnlands zu hemmen, sondern im Sinne der litauischen Regierung eher vorsichtig zu fördern. Noch vor Zusammentritt der Außenminister Estlands, Lettlands und Litauens in Riga hatte Maksim Litvinov, der damals sein Land als sowjetischer Bevollmächtigter in Reval vertrat, dem estnischen Außenminister zu verstehen gegeben, daß Sowjetrußland einer Verständigung zwischen den drei baltischen Staaten nicht im Wege stehe, sondern ausschließlich in der Teilnahme Polens an einem Randstaatenbund - Finnland ließ er unerwähnt - eine gegen die Sowjetregierung gerichtete Politik sehe. Während der Rigaer Besprechungen hatte der sowjetische Vertreter in Lettland, Ganeckij ${ }^{65}$, diesen Standpunkt seiner Regierung gegenüber Piip, Meierovics und Purickis noch einmal ausdrücklich bekräftigt ${ }^{66}$.

Der wohlwollenden Stellungnahme von sowjetischer Seite gegenüber Bündnisvereinbarungen zwischen Litauen, Lettland und Estland entsprachen auf polnischer Seite

61 Vgl. Georg von Rauch, Geschichte der baltischen Staaten, Stuttgart, Berlin, Köln, Mainz 1970, S. 99.

62 Ber. Nr. 59/21 v. Hentig, Reval, 16. VII. 1921, PA, IV Rd, Pol 3, Est/Lett, Bd. 1.

63 Ebenda und Ber. Nr. Ko 538 v. Köster, Riga, 8. XII. 1923, PA, IV Rd, Pol 4, Geheimakten, Bd. 2. Vgl. auch Edgar Anderson, Toward the Baltic Union, 1920-1927, in: Lituanus 12, 2 (1966), S. $35 \mathrm{ff}$.

64 Arumjaè, S. 122; Skrzypek, Zwiạzek baltycki, S. 108.

65 Vgl. Biographischer Anhang.

${ }^{66}$ Skrzypek, Związek bałtycki, S. 125. 
Mißtrauen und Beunruhigung. Allerdings wurden die Chancen eines Zusammenschlusses der drei baltischen Staaten innerhalb der polnischen Diplomatie durchaus unterschiedlich bewertet. Kamieniecki glaubte nach der Unterzeichnung des estnischlettischen Bündnisvertrages an den baldigen Abschluß eines analogen lettisch-litauischen Vertrages und sah hierin den Beginn der Bildung eines kleinen Randstaatenbundes, der den Interessen Polens gefährlich werden müßte. Ein Bündnis zwischen Litauen, Lettland und Estland, begründete er Anfang Juli 1921 gegenüber dem polnischen Außenministerium seine Befürchtungen, stelle ein Verbindungsglied zwischen Deutschland und Rußland her und bedeute eine Einkreisung Polens von Norden. Als einzigen Ausweg aus dieser verhängnisvollen Entwicklung empfahl er eine schnelle und gewaltlose Beilegung des Wilnakonfliktes, wobei er ein eigenes, wenig realistisches Projekt entwickelte, welches gewissermaßen auf eine Ausweitung des HymansPlanes auf alle nördlichen Randstaaten hinauslief und hierüber auf die Herstellung eines Polen, Litauen, Lettland, Estland und Finnland umfassenden großen Randstaatenbundes abzielte, in dem Polen das natürliche Schwergewicht zufallen müßte ${ }^{67}$. Optimistischer fiel demgegenüber die Einschätzung der baltischen Randstaatenbündnispläne in der Ostabteilung des Warschauer Außenministeriums aus. Infolge der prodeutschen und prosowjetischen Tendenzen der litauischen Außenpolitik hielt man dort ein Bündnis Litauens mit Lettland und Estland für wenig wahrscheinlich ${ }^{68}$. Insgesamt bereitete die bisherige Entwicklung in der Randstaatenfrage der polnischen Regierung trotz der erfolglosen Bündnisverhandlungen zwischen den Außenministern Estlands, Lettlands und Litauens Sorge und Unbehagen. Skirmunt brachte dies in einem Runderlaß an alle polnischen Auslandsvertretungen vom 2. August $1921 \mathrm{mit}$ der Feststellung zum Ausdruck: ,Lettland und Estland haben bewiesen, daß sie dem Gefühl einer gewissen Stammessolidarität gegenüber Litauen nicht entsagen wollen oder können. Dies beweist die Zwiespältigkeit und Inkonsequenz ihrer Politik gegenüber Polen" ${ }^{\text {"69. }}$.

\section{Die Konferenz von Helsinki}

\section{Einberufung und Verlauf der Konferenz}

Um den Tendenzen zu einem Zusammenschluß der drei baltischen Staaten entgegenzuwirken, hatte das polnische Außenministerium bereits am 26. Mai 1921 eine Instruktion ausgearbeitet, welche die Einberufung einer Konferenz der Außenminister Polens, Lettlands, Estlands und Finnlands für August 1921 nach Warschau vorsah ${ }^{70}$.

${ }^{67}$ Skrzypek, Związek baltycki, S. $106 \mathrm{f}$. Interview Kamienieckis für die lettische Telegraphenagentur LTA vom 28. V. 1921 (Ber. Ko Nr. 171 v. Radowitz, Riga, 2. VI. 1921, PA, IV Rd, Pol 3, Lit/Po, Bd. 2/II. Serie/). Vgl. auch Witold Kamieniecki, La Pologne sur la Baltique, in: Les Problèmes de la Baltique, Paris 1934, S. 68 f.

68 Skrzypek, Związek bałtycki, S. 107.

69 Instrukcja ogólna dla placówek, 3. VIII. 1921, in: Zeszyty Historyczne 22 (1972), S. 96-102, hier S. 100.

70 Skrzypek, Związek bałtycki, S. 109. 
Noch während die polnische Regierung mit den Vorbereitungen auf diese Konferenz beschäftigt war, fand sie in dieser Frage in der finnischen Regierung einen geeigneten Verbündeten, der seinerseits und aus eigener Initiative eine Konferenz der vier Außenminister bereits für die Zeit vom 25. bis zum 29. Juli 1921 nach Helsinki einberief. Mit dieser Entscheidung kam Finnland der polnischen Regierung zuvor. Die finnische Regierung hatte von der Absicht Dąbskis erfahren, zu Vorgesprächen nach Helsinki zu kommen, worauf sie, um die politischen Besprechungen auf eine breitere Grundlage zu stellen, sogleich die Außenminister Lettlands und Estlands ebenfalls zur Teilnahme eingeladen hatte ${ }^{71}$.

Der Entschluß der finnischen Regierung zu diesem Schritt war jedoch erst erfolgt, nachdem die schwedische Regierung zuvor eine engere Verbindung zu Finnland oder zu den baltischen Staaten für grundsätzlich unvereinbar mit ihrer traditionell neutralistischen Politik erklärt hatte ${ }^{72}$. Da das finnisch-schwedische Verhältnis zudem noch durch die Åland-Frage belastet war ${ }^{73}$, nahm die schwedische Außenpolitik gegenüber finnischen Annäherungsbemühungen außerdem eine von Vorsicht bestimmte ablehnende Haltung ein ${ }^{74}$. Aus diesen Gründen verfolgte die finnische Regierung von nun an verstärkt eine auf die baltischen Staaten und insbesondere Polen ausgerichtete außenpolitische Orientierung. Die polnische Diplomatie hatte diese Tendenzen der finnischen Außenpolitik bisher dadurch indirekt zu fördern gesucht, daß sie in der Åland-Frage den finnischen gegen den schwedischen Standpunkt unterstützte ${ }^{75}$.

Auf der Konferenz in Helsiniki dominierte die Frage des Verhältnisses der vier Teilnehmerstaaten gegenüber Sowjetrußland. Während der fünftägigen Besprechungen erreichte Polen eine weitgehende außenpolitische Zusammenarbeit der beteiligten vier Regierungen in dieser Frage. Die Delegationen verpflichteten sich, ihre Politik gegenüber Rußland untereinander zu koordinieren und sich gegenseitig über die politischen Vorgänge in Rußland zu informieren. In dieser Hinsicht war Polen, wie bereits erwähnt, als treibende Kraft eines engeren Zusammenschlusses der vier Mächte erstmals erfolgreich in Erscheinung getreten ${ }^{76}$.

Abgesehen von dieser gegen Sowjetrußland demonstrierten Einigkeit der vier Regie-

71 Ber. 734 v. Wallroth, Helsinki, 19. VIII. 1921, PA, IV Nd, Pol 3, Fi/Ru, Bd. 1 (II. Serie).

72 A.S. Kan, Nejtralistskie tradicii vo vnešnej politike skandinavsskich gosudarstv, in: Novaja i novejšaja istorija 4 (1962), S. 77; Jorma Kalela, Grannar på skilda vägar, Helsinki 1971, S. 63.

73 Die Ålandinseln gehörten seit 1809 zusammen mit Finnland zum Russischen Reich. Seit der Mitte des 19. Jahrhunderts hat die Lage der Inseln sowie der Umstand, daß sie politisch zu Finnland gehören, $96 \%$ ihrer Bevölkerung jedoch schwedisch sprechen, zu besonderen völkerrechtlichen Regelungen geführt. Als Finnland im Dezember 1917 seine Unabhängigkeit erklärte und die Ålandinseln beanspruchte, entschieden sich die Bewohner der Inselgruppe - etwas mehr als 20000 Menschen - in einer Volksabstimmung für eine Vereinigung mit Schweden. Am 24. Juni 1921 wurde in einer Entscheidung des Völkerbundes der Anspruch Finnlands auf die Ålandinseln bestätigt.

74 Erik Lönnroth, Den svenska utrikes politikens Historija, Bd. 5 (1919-1939), Stockholm 1959, S. 61.

75 Skrzypek, Związek baltycki, S. 136, Anm. 44.

76 Vgl. S. $54 \mathrm{f}$. 
rungen zeigten sich in der Frage, mit welchen konkreten Schritten die Bildung eines Randstaatenbundes voranzutreiben sei, weitgehende Meinungsunterschiede, die sich aus den unterschiedlichen Konzeptionen der beteiligten Mächte ergaben. Die estnische Delegation unter Außenminister Piip machte die entschiedensten und weitreichendsten Vorschläge. Ohne Litauen zu erwähnen, demgegenüber das Interesse der estnischen Politiker nach den Rigaer Besprechungen und insbesondere nach Hinzuziehung Finnlands spürbar geringer geworden war, setzte sie sich für zwei- oder mehrseitige politische und militärische Verträge zwischen den Teilnehmerstaaten ein. Der finnische Außenminister und Konferenzleiter Holsti war wesentlich zurückhaltender und plädierte zunächst für eine weitere politische Annäherung der vier Regierungen ${ }^{77}$. Meierovics vertrat demgegenüber schließlich den Standpunkt, daß der Ausarbeitung konkreter Pläne zur Bildung einer Randstaatenföderation die Hinzuziehung Litauens zu künftigen Konferenzen vorausgehen müsse. Aus diesem Grunde sprach er sich gegen politische und militärische Verträge aus ${ }^{78}$. Auch die polnische Delegation mit Dąbski an der Spitze war nicht bereit, militärische Verpflichtungen gegenüber den schwächeren baltischen Staaten zu übernehmen und begründete ihre Haltung mit der Position des Verbündeten Rumänien, die zuvor geklärt werden müßte ${ }^{79}$. Im übrigen bemühte sich die polnische Delegation um eine engere Zusammenarbeit mit Estland und Finnland, um auf die lettische Regierung Druck auszuüben und sie auf diese Weise von vertraglichen Bindungen zu Litauen abzuhalten ${ }^{80}$.

Wegen der Unvereinbarkeit der von den vier Delegationen vorgetragenen Stellungnahmen endete die Helsinkikonferenz in der Randstaatenfrage ohne greifbare Ergebnisse. Entschließungen über Handels-und Verkehrsfragen blieben bloße Empfehlungen. Politische Verträge irgend welcher Art wurden nicht abgeschlossen. Vereinbart wurde lediglich, sich gegenseitig über Verhandlungen zwischen den an der Konferenz beteiligten Mächten zu informieren und periodische Außenministerbesprechungen abzuhalten ${ }^{81}$.

\section{Polen und die Konferenzergebnisse}

Während die polnische Regierung insgesamt die weitgehende Isolierung Litauens unter den baltischen Staaten als einen wesentlichen Erfolg ihrer Randstaatenpolitik

77 Ber. 734 v. Wallroth, Helsinki, 19. VIII. 1921, PA, IV Nd, Pol 3, Fi/Ru, Bd. 1 (II. Serie).

${ }^{78}$ Arumjaè, S. $126 \mathrm{f}$.

79 Arumjaè, S. 126, 128.

80 In einem Bericht eines Vertrauensmannes über die Konferenz in Helsinki an den Oberpräsidenten der Landeskriminalpolizei Königsberg vom 20. August 1921, der an das Auswärtige Amt in Berlin weitergeleitet wurde, hieß es: „Lettlands Versuche, dorthin auch eine Aufforderung Litauens durchzusetzen, scheiterten, und es konnte sogar festgestellt werden, daß die polnischen Vertreter in Helsingfors nicht nur gegen Litauen Stimmung machten, sondern auch gegen Lettland in vertraulichen Separatzusammenkünften mit den Delegierten Finnlands und Estlands intrigierten“. PA, IV Rd, Pol 3, Lit/Po, Bd. 2 (II. Serie).

81 Alfred Bihlmans, Die politischen und wirtschaftlichen Grundlagen der baltischen Republik Lettland, Riga 1926, S. 41; Royal Institute of International Affairs, The Baltic States, London, New York, Toronto 1938, S. 67; Failure of the Baltic League, in: Current History 14 (1921), S. $1062 \mathrm{f}$. 
betrachtete, wurden jene Ergebnisse der Konferenz von Helsinki, die sich unmittelbar auf das Verhältnis der Konferenzteilnehmer zu Sowjetrußland bezogen, innerhalb der polnischen Regierung unterschiedlich bewertet. Der Beschluß, die außenpolitischen Schritte Polens, Finnlands, Estlands und Lettlands gegenüber Sowjetrußland zu koordinieren, wurde in erster Linie von jenen polnischen Delegationsmitgliedern begrüßt, die als Anhänger Piłsudskis in der Konzeption eines gegen Rußland gerichteten Randstaatenbundes das wichtigste Ziel der polnischen Diplomatie in Nordosteuropa sahen. Zu Piłsudskis Anhängern zählten mit Ausnahme Dąbskis, der ebenso wie Skirmunt und die polnische Nationaldemokratie keine die Interessen Sowjetrußlands herausfordernde Randstaatenpolitik Polens befürworte, alle übrigen drei Mitglieder der polnischen Delegation: der Leiter der Ostabteilung im Außenministerium Juliusz Łukasiewicz $^{82}$, der Leiter des Referats für baltische Angelegenheiten im Außenministerium Tytus Komarnicki ${ }^{83}$ sowie der langjährige persönliche Vertraute Piłsudskis und damalige Gesandte Polens in Finnland Michał Sokolnicki ${ }^{84}$.

Das Übergewicht des Belvedere innerhalb der polnischen Regierungsdelegation hatte den Verlauf und die Taktik der polnischen Verhandlungsführung in Helsinki maßgeblich geprägt. Die ganz in den Vordergrund der Konferenz gerückte Frage des Verhältnisses aller Randstaaten zu Sowjetrußland einerseits und die ausdrückliche Erwähnung des mit Polen politisch und militärisch verbündeten Rumänien andererseits ließen darauf schließen. Aus dem Argument nämlich, zunächst die Haltung der rumänischen Regierung zu klären, sprach eindeutig die Konzeption Piłsudskis und seiner Anhänger nach einer Verbindung aller Nachbarstaaten Sowjetrußlands von der Ostsee im Norden bis zum Schwarzen Meer im Süden. Dieses Argument gestattete den Piłsudski-Anhängern darüber hinaus auch, die polnische Politik gegenüber den baltischen Staaten solange nicht festzulegen, als die Ziele eines Randstaatenbundes nicht mit den politischen Zielen des polnischen Staatschefs im Einklang standen. Insofern konnte die abwartende Haltung der polnischen Delegationsmitglieder durchaus auch Einfluß auf die Bündnispläne der übrigen Teilnehmerstaaten gewinnen.

Die Einschätzung der Konferenzergebnisse durch die genannten Delegationsmitglieder formulierte deutlich Łukasiewicz. Er vermerkte zunächst, daß durch die erfolgreiche Isolierung Litauens alle Versuche gelähmt worden seien, ein lettisch - litauisch estnisches Bündis herbeizuführen. Lettland sei klar gemacht worden, daß es in der Randstaatenpolitik auf Polen Rücksicht nehmen müsse. Während der Konferenz habe sich weiterhin herausgestellt, daß Finnland in keinem Falle einem Randstaatenbündnis ohne Polen beitreten werde. Alle diese Tatsachen, folgerte Lukasiewicz, hätten zu einer erfolgreichen diplomatischen Front gegenüber Sowjetrußland geführt. Damit sei der Beweis erbracht worden, daß Polen im Baltikum über bedeutendes Prestige verfüge und seine Einflüsse in dieser Region größer seien als die Rußlands. Ohne Deutschland und Frankreich zu erwähnen, stellte er schließlich mit Befriedigung fest,

82 Vgl. Biographischer Anhang.

83 Vgl. Biographischer Anhang.

84 Vgl. Biographischer Anhang. 
es habe von seiten der britischen Regierung keinerlei Widerstand gegen die Ergebnisse der Konferenz gegeben ${ }^{85}$.

Eine diplomatische Intervention der britischen Regierung gegen ein erneutes und verstärktes antisowjetisches Engagement Polens im Baltikum war bei der ablehnenden Haltung Londons den bisherigen polnischen Randstaatenplänen gegenüber durchaus zu erwarten gewesen. Über die Rolle Polens auf der Konferenz von Helsinki wurde indes das Foreign Office durch die britische Gesandtschaft in Warschau nur unzureichend in Kenntnis gesetzt. Offensichtlich aufgrund mangelnder Informationen beschränkte sich der Gesandte Max Muller darauf, die zurückhaltende Beurteilung der Konferenzergebnisse durch Außenminister Skirmunt wiederzugeben, ohne jedoch darauf hinzuweisen, daß eben diese Ergebnisse im wesentlichen auf polnische Initiativen zurückzuführen waren: „The Polish Government were not moved to enthusiasm by the results of this conference.... M. Skirmunt seemed apprehensive of the possible dangers involved in a defensive alliance against Russia, and differed from the view taken in this respect by Prince Sapieha earlier in the year ${ }^{686}$. Mullers gleichzeitiger Hinweis auf die unterschiedlichen Auffassungen zwischen Skirmunt und dessen Amtsvorgänger Sapieha reichten keinesfalls aus, der britischen Regierung ein klares Bild von dem tatsächlich verstärkten antirussischen Einfluß Polens in den nördlichen Randstaaten zu vermitteln. Seine Berichterstattung bewirkte eher das Gegenteil. Indem er die skeptische Stellungnahme Skirmunts, die in London zweifellos mit Befriedigung aufgenommen wurde, als einzige maßgebende offizielle Beurteilung der polnischen Regierung hervorhob, mußte er dort den irrigen Eindruck hervorrufen, als sei die gegenwärtige polnische Regierung am Zustandekommen der Konferenzergebnisse selbst nicht führend beteiligt gewesen. Aus diesem Grunde sah London offenbar auch keinen Anlaß, bei der polnischen Regierung Einwände geltend zu machen.

Anders als in London lösten die Ergebnisse der Helsinkikonferenz in Berlin erhebliche Unruhe aus. Zwar wußte die Reichsregierung sehr genau, daß die Randstaatenpläne Polens, Finnlands, Estlands und Lettlands sich insgesamt in erster Linie gegen Rußland richteten. Auch die Beschlüsse der Helsinkikonferenz hatten diese Tendenz erneut bestätigt. Was im Auswärtigen Amt aber zu Beunruhigung Anlaß gab, waren die Rückwirkungen der polnischen Randstaatenpolitik auf Deutschland. Die deutsche Diplomatie fürchtete den polnischen Machtzuwachs, der die Stellung Polens auch im Hinblick auf eine Auseinandersetzung mit Deutschland stärken mußte. Die wachsenden Einflüsse Polens in den baltischen Staaten und in Finnland schienen dem Auswärtigen Amt um so gefährlicher, als die französische Politik gleichzeitig bemüht war, die antideutschen Rückwirkungen der polnischen Randstaatenpolitik im Sinne ihrer Politik des cordon sanitaire zwischen Deutschland und Sowjetrußland besonders zu unterstützen ${ }^{87}$.

${ }^{85}$ Lewandowski, Imperializm słabości, S. $184 \mathrm{f}$.

86 Rep. No. 582 v. Sir Max Muller, Warschau, 23. XII. 1922, Poland. Annual Report, 1921, PRO, F. O. 371/ 9312/ N 30/30/55, S. 21, par. 114.

${ }^{87}$ Ber. v. Schoen, Warschau, 13. IX. 1921, Politische Übersicht Nr. 36 v. 24. IX. 1921, PA, Büro RM, 68, Bd. 1. 
Der gegen Deutschland gerichteten Spitze der Randstaatenbündnispolitik, die neben Frankreich insbesondere von der polnischen Nationaldemokratie gefördert wurde, suchte die deutsche Außenpolitik nach Kräften entgegenzuwirken. In Frankreich und in Polen selbst war dies nicht möglich. Auch der Einfluß der deutschen Politik auf Lettland und Estland war begrenzt, und das vergleichsweise deutschfreundliche Litauen an der Helsinkikonferenz ohnehin nicht beteiligt. Sehr viel bedeutendere Einflußmöglichkeiten boten sich dagegen der deutschen Außenpolitik in Finnland. Die finnische Öffentlichkeit, insbesondere die finnischen Rechtsparteien, waren deutschen Argumenten gegenüber aufgeschlossen, obwohl gerade sie militärische Vereinbarungen mit Polen als eine Sicherung vor Sowjetrußland befürworteten. Um der Orientierung der finnischen Außenpolitik zu den Randstaaten und nach Polen entgegenzuwirken, suchte die Reichsregierung in der finnischen Öffentlichkeit die Rußlandfurcht abzuschwächen. Der finnischen Rechten gegenüber die russische Gefahr zu bagatellisieren, war freilich wenig erfolgreich. Als wesentlich wirkungsvoller erwiesen sich dagegen die deutschen Bemühungen, die Hinwendung Holstis zu den Randstaaten und Polen auf einen Druck der Entente und insbesondere Frankreichs zurückzufüh$\mathrm{ren}^{88}$. Daß die deutschen Anstrengungen in dieser Richtung auf die finnische Regierung Eindruck machten, konnte der deutsche Geschäftsträger in Helsinki, Wallroth, alsbald nach Berlin berichten. Ihm gegenüber wandte sich der Kanzleichef des finnischen Außenministeriums, Pontus Artti, ,mit aller Entschiedenheit“" gegen die deutsche Auffassung, wonach „Finnland sich in den Randstaatenbund als eine von Frankreich inaugurierte ,ceinture de force' hineinpressen lassen werde“" und erklärte nachdrücklich, Finnland würde sich an keiner gegen Deutschland gerichteten Politik beteiligen ${ }^{89}$.

\section{Sowjetrußland, Litauen und die Konferenzergebnisse}

Die sowjetische Regierungspresse reagierte auf die Beschlüsse der Konferenz von Helsinki sofort mit der Behauptung, der Plan eines Baltenbundes unter Teilnahme Polens stelle einen Sieg der französischen Diplomatie dar. Eine Verwirklichung dieses Planes bedeute nicht die Bildung eines Verteidigungs- sondern eines Angriffsbündnisses, da nur im Falle eines Bündnisses zwischen kleinen Staaten - gemeint waren Litauen, Lettland und Estland - von einer Verteidigungsallianz gesprochen werden könne ${ }^{90}$.

${ }^{88}$ Die Reichsregierung bediente sich vor allem der liberalen „Frankfurter Zeitung“, um ihre Auffassungen zu verbreiten, da dieses Blatt in Finnland als die maßgebende deutsche Zeitung galt. Insbesondere das schwedischsprachige „Hufvudstadsbladet“ griff die deutschen Befürchtungen vor einem finnisch-polnisch-baltischen Staatenbündnis auf und warnte vor der Gefahr einer deutsch-finnischen Entfremdung. Vgl. hierzu Hannes Saarinen, Finnland und die Außenpolitik der Weimarer Republik, (phil. Diss.) Berlin 1973, S. 133-138.

89 Ber. Nr. 734 v. Wallroth, Helsinki, 19. VIII. 1921, PA, IV Nd, Pol 3, Fi/Ru, Bd. 1 (II. Serie).

90 Izvestija v. 29. VII. 1921. Tel. v. Stähler, Moskau, 5. VIII. 1921, PA, IV Ru, Pol 2, Ru/Dt, Bd. 5, Bl. 168. Vgl. auch Iz godovogo otčeta NKID RSFSR $k$ IX s-ezdu sovetov za 1920-1921, in: DVP IV, S. 697; Rodgers, S. 21. 
Bei aller verständlichen Sorge der Sowjetregierung vor einer engeren Zusammenarbeit zwischen den baltischen Staaten, Finnland und Polen, war eine Deutung der Konferenzergebnisse von Helsinki in diesem Sinne zweifellos übertrieben. Von der Bildung eines „Angriffsbündnisses“ konnte bei dem Stand der vertraglichen Vereinbarungen zwischen den Konferenzteilnehmern überhaupt keine Rede sein. Die Bemerkung des sowjetischen Regierungsorgans über einen angeblichen Sieg der französischen Diplomatie in der Frage eines Baltenbundes unter Einschluß Polens traf nur sehr bedingt zu. An einer engeren Zusammenarbeit zwischen Polen, Finnland und den baltischen Staaten zeigte die französische Diplomatie seit dem Abschluß des polnisch-französischen Bündnisvertrages vom 19. Februar 1921 ein grundsätzliches Interesse ${ }^{91}$. Ähnlich der polnischen Nationaldemokratie galt jedoch das Hauptaugenmerk der französischen Randstaatenpolitik in erster Linie der Zurückdrängung deutscher Einflüsse in Finnland und den baltischen Staaten ${ }^{92}$. Für die Bildung eines antisowjetischen Randstaatenblocks im Sinne Pilsudskis schien sie dagegen aufgrund ihrer erheblichen Vorbehalte gegen die ostpolitischen Pläne und Absichten des polnischen Staatschefs keine aktive diplomatische Unterstützung geleistet zu haben ${ }^{93}$.

Wesentlich schärfere Formulierungen als die sowjetische Regierungspresse gebrauchte wenig später Litvinov in Reval gegenüber dem estnischen Außenminister Piip. Als die Leiter der Delegationen vereinbarungsgemäß am 25. August 1921 erneut in Helsinki zusammentrafen, um gemeinsam gegen die Nichteinhaltung verschiedener friedensvertraglicher Verpflichtungen durch die Sowjetregierung zu protestieren, berichtete Piip, Litvinov habe eine Erklärung abgegeben, in der er festgestellt habe, der Abschluß eines Bündnisvertrages zwischen irgendeinem der baltischen Staaten und Polen würde von der Sowjetregierung als casus belli betrachtet ${ }^{94}$. Diese mit Entschiedenheit vorgetragene Erklärung Litvinovs war sicherlich nicht ohne Kenntnis des Verlaufs der Konferenz von Helsinki abgefaßt worden. Sie bedeutete im Hinblick auf die Uneinigkeiten unter den Konferenzteilnehmern in der Randstaatenfrage eine Warnung an die baltischen Staaten, sich den Zielen einer gegen Sowjetrußland gerichteten polnischen Randstaatenpolitik unterzuordnen und zeigte die Entschlossenheit der Sowjetregierung, jeder Bildung eines polnisch-baltischen Randstaatenblocks an ihren Westgrenzen Widerstand entgegenzusetzen. Zugleich warf die Erklärung auch ein bezeichnendes Licht auf die Frage eines Randstaatenbundes überhaupt. Die Bildung einer Randstaatenföderation mit Einschluß Polens konnte für die baltischen Staaten und für Finnland das Risiko erhöhen, in eine militärische Auseinandersetzung mit Sowjetruß-

91 Benjamin Goriely, L'Union soviétique et la Pologne, in: Les frontières européennes de l'U.R. S. S., Paris 1957, S. 225 f.

92 Vgl. Kukułka, S. 553.

93 Der sowjetestnische Historiker Chejno Arumjaè (S. 131) bekräftigt die These von der französischen Unterstïtzung für ein polnisch-baltisches Angriffsbündnis. Er führt hierfür indes keine neuen Beweise an, sondern stützt seine Argumentation ausschließlich auf die bereits in anderem Zusammenhang widerlegte Behauptung einer angeblichen Note der französischen Regierung an Polen und Rumänien vom 3. September 1921 (vgl. S. 80-89).

94 Starzewski, S. 76. Vgl. Pobóg-Malinowski II, S. 404. 
land verwickelt zu werden, gegen die sich diese Staaten durch eine engere Verbindung mit Polen ja gerade schützen wollten.

Mit der offensichtlichen Absicht, dieses Risiko zu unterstreichen, also den baltischen Staaten und Finnland die Gefährlichkeit ihrer außenpolitischen Zusammenarbeit mit Polen vor Augen zu führen, ließ die Sowjetregierung an ihren Westgrenzen starke Truppenverbände zusammenziehen. Über deren Bedeutung und Zielsetzung machte die Sowjetregierung selbst keinerlei Angaben und erzeugte somit in den baltischen Staaten und Finnland das beabsichtigte Gefühl der Unsicherheit. Die ersten Nachrichten über russische Truppenansammlungen verbreitete am 18. Juli 1921 die britische Nachrichtenagentur Reuter mit einer Meldung aus Helsinki. Darin hieß es, Reuter besitze zuverlässige Nachrichten darüber, daß die Sowjetregierung eine allgemeine Mobilmachung angeordnet habe, die sich gegen Estland, Lettland und Litauen richte ${ }^{95}$. In deutschen Pressemeldungen wurde die Nachricht über eine Gesamtmobilmachung Sowjetrußlands zwar nicht in Frage gestellt, aber die Vermutung ausgesprochen, daß sich diese gegen Polen richte ${ }^{96}$.

In Finnland, den baltischen Staaten und Polen wurden die Nachrichten über sowjetische Truppenmassierungen unterschiedlich beurteilt. Während die Regierungen Lettlands und Finnlands über verschiedene diplomatische Kanäle zwar die Meldungen über sowjetische Truppenkonzentrationen an ihren östlichen Grenzen besorgt bestätigten, aber keine Anzeichen für russische Mobilmachungsmaßnahmen zu erkennen vermochten ${ }^{97}$, interpretierte die litauische Regierung die sowjetischen militärischen Demonstrationen weitaus dramatischer. Wenige Tage nach der Konferenz von Helsinki unterrichtete Purickis in einer vertraulichen Unterredung den deutschen Gesandten in Litauen, Schönberg, er habe von seinem Gesandten in Moskau, Jurgis Baltrušaitis $^{98}$, ganz sichere Nachrichten erhalten, daß das sowjetische Zentralexekutivkomitee am 16. Juli 1921 beschlossen habe, Polen zu besetzen und die Regierung mit der Ausführung dieses Beschlusses beauftragt habe. Die Mobilmachung werde bereits durchgeführt und der Beschluß sei damit begründet worden, daß Rußland sich gewaltsam Nahrungsmittel beschaffen müsse. Purickis fügte hinzu, Polen scheine von diesem Beschluß Kenntnis zu haben, denn es konzentriere Truppen im Raume Dünaburg - Wilna, setzte Wilna in Verteidigungszustand, zerstöre nach Rußland führende Brücken und treffe sonstige Abwehrmaßnahmen. Zugleich äußerte Purickis dabei die Auffassung, daß er in einem erneuten polnisch-sowjetischen Krieg zwar große Erleichterung im Hinblick auf den gegenwärtigen litauisch-polnischen Streit sehe. Er glaube aber nicht, daß Sowjetrußland gleichzeitig auch die baltischen Staaten angreifen werde. Litauen sei jedoch über die spätere Entwicklung besorgt und werde für alle

\footnotetext{
95 Reuter-Meldung aus Helsinki v. 18. VII. 1921, PA, IV Po, Pol 3, Ru/Po, Bd. 2, Bl. 216.

96 „Der Tag“ Nr. 334 vom 18. VII. 1921, ebenda.

97 Vertrauliche Mitteilungen des finnischen Geschäftsträgers in Madrid an die dortige deutsche diplomatische Vertretung (Tel. Nr. 419 v. Langwerth, Madrid, 23. VIII. 1921, ebenda, Bl. 225). Ber. Nr. A-1786 v. Radowitz, Riga, 19. IX. 1921, ebenda, Bl. 288.

98 Vgl. Biographischer Anhang.
} 
Fälle Truppen an seiner östlichen Grenze bereithalten und mit der lettischen Regierung über gemeinsame Abwehrmaßnahmen beraten ${ }^{99}$.

Das Auswärtige Amt in Berlin, das bereits seit April 1921 immer wieder dort auftauchende Meldungen über militärische Vorbereitungen Sowjetrußlands gegen Polen durch seine Vertretung in Moskau nachprüfen ließ, ohne jedoch bisher irgend welche Anhaltspunkte für ihre Bestätigung ermitteln zu können ${ }^{100}$, wies aufgrund der neuesten Informationen die deutschen Gesandtschaften in Moskau und Warschau erneut an, die Nachrichten über russische Mobilisierungsmaßnahmen bzw. polnische Abwehrvorkehrungen einer genauen Überprüfung zu unterziehen. Am 9. August 1921 telegraphierte die Vertretung in Moskau nach Berlin, die Sowjetregierung habe in der Tat die Mobilmachung von 50 Prozent der Jahrgänge 1898 und 1899 angeordnet und deren Meldegestellungspflicht auf 24 Stunden begrenzt ${ }^{101}$. Die Gesandtschaft in Warschau meldete am 12. August 1921 nach intensiven Nachforschungen, sie könne trotz eingehender Beschäftigung der polnischen Regierung und der polnischen Presse mit russischen Fragen und insbesondere mit der Hungersnot in Rußland ${ }^{102}$ keine Anzeichen für eine Besorgnis vor kriegerischen Verwicklungen mit Sowjetrußland erkennen. Allerdings hätte der polnische Generalstabschef Sikorski eine Automobilreise mit geheim gehaltenem Ziel angetreten, die möglicherweise mit militärischen Vorbereitungen im Nordosten Polens in Verbindung gebracht werden könnte ${ }^{103}$.

Von starken polnischen Truppenverschiebungen nach Nordosten, in den Raum von Lida - Mołodeczno, hatte auch der Quai d'Orsay erfahren und beunruhigt bei der polnischen Gesandtschaft in Paris nach Ziel und Zweck der Militärtransporte anfragen lassen. Die polnische Gesandtschaft beruhigte das französische Außenministerium am 30. Juli 1921 mit der Erklärung, es handele sich bei den Truppentransporten um Maßnahmen zum verstärkten Schutz des östlichen Korridors zwischen Litauen und Sowjetrußland. Diese Vorsorgemaßnahmen seien nötig geworden ,en raison des ro-

99 Ganz geheimes Tel. Nr. 69 v. Schönberg, Kowno, 5. VIII. 1921, PA, IV Po, Pol 3, Ru/Po, Bd. 2, Bl. 211.

100 Tel. Nr. 122 von Ministerialdirektor Behrendt an die deutsche Vertretung in Moskau v. 18. IV. 1921, PA, IV Ru, Pol 13, Bd. 1. Am 28. IV. 1921 antwortete die Vertretung in Moskau mit der Feststellung: ,Jede russische Mobilmachung würde fraglos jetzt auf größtes Hindernis stoßen“. Tel. Nr. 199 v. Hilger, ebenda.

101 Tel. Nr. 445 v. Stähler, Moskau, PA, IV Ru, Pol 2, Ru/Dt, Bd. 5, Bl. 169.

102 Im Zusammenhang mit der Hungersnot in Rußland forderte der nationaldemokratische „Dziennik Poznański“ (Nr. 146 v. 21. VII. 1921) die polnische Öffentlichkeit zur Zurückstellung der parteipolitischen Unterschiede und zu erhöhter Wachsamkeit gegenüber Sowjetrußland auf. Warnend fügte der „Dziennik Poznański“ hinzu: „Polen muß dauernd unter der Drohung der östlichen Ereignisse leben. Es ist in hohem Grade abhängig von den unberechenbaren Bewegungen des kranken Riesen, dessen Gehirn bösartig ist, dessen Hände lang sind und dessen Kraft zwar desorganisiert, aber immer noch ungeheuer ist". Zur Hungersnot in Rußland: H. H. Fischer, The Famine in Russia, 1919-1923, The Operations of the American Relief Administration, New York, 1927.

103 Ber. Nr. 373 v. Dirksen, Warschau, PA, IV Ru, Pol 3, Ru/Po, Bd. 2, Bl. 220. 
domontades bolchéviques actuelles et comme mesure de précaution contre la forte migration d'affamés qui s'avance de l'Est" ${ }^{\text {"104. }}$.

Die überraschenden und dramatischen Mitteilungen Purickis' an den deutschen Vertreter in Kowno wurden kurze Zeit später von ihm selbst wieder abgeschwächt. In einer erneuten Unterredung mit Schönberg, über deren Inhalt dieser am 24. August 1921 dem Auswärtigen Amt Bericht erstattete, hielt Purickis aufgrund der neuesten Berichte des litauischen Gesandten in Moskau - im Gegensatz zu seiner vorherigen Auffassung - ,einen russischen Angriff auf Polen in diesem Jahr nicht mehr für wahrscheinlich". Er bestätigte dabei allerdings gleichzeitig die Informationen der deutschen Gesandtschaft in Moskau über eine russische Teilmobilmachung, deren Umfang er auf 200000 Mann bezifferte. Um seine zuvor getroffenen Aussagen noch weiter einzuschränken, erklärte er dem deutschen Gesandten außerdem, daß nach seinen Informationen auch der sowjetische Vertreter in Kowno, Aralov, an baldige russische Angriffsabsichten nicht zu glauben scheine ${ }^{105}$.

Die Äußerungen des litauischen Außenministers ließen erkennen, daß er mit der Betonung von angeblich in erster Linie gegen Polen gerichteten sowjetischen Truppenaufmärschen die baltischen Nachbarn von einer weiteren Annäherung an Polen abzubringen beabsichtigte. Da die Sowjetregierung das gleiche Ziel verfolgte, ist zumindest die Möglichkeit nicht ganz ausgeschlossen, daß sie selbst dem litauischen Vertreter in Moskau Informationen über angeblich bevorstehende russische Angriffsabsichten gegen Polen zukommen ließ. Ihre Weiterleitung an Lettland und Estland konnte die Sowjetregierung aufgrund der Bestrebungen der litauischen Regierung nach einem litauisch-lettisch-estnischen Bündnis durchaus erwarten. Womöglich versprach sie sich hiervon ein gemeinsames Abrücken der drei baltischen Staaten von Polen und eine stärkere Förderung des von ihr unterstützten litauischen Standpunktes in der Randstaatenfrage. Näher liegt allerdings der von Schönberg geäußerte Verdacht, daß der litauische Außenminister durch die absichtlich und bewußt als Kriegsvorbereitungen gegen Polen gedeuteten russischen Mobilisierungsmaßnahmen von sich aus eine Annäherung an Lettland zu fördern suchte, um die auf der Konferenz in Helsinki zutage getretene außenpolitische Isolierung seines Landes zu durchbrechen und sich einen, wenn auch schwachen Rückhalt gegen Polen zu sichern. Purickis' Absichten erhielten insofern eine gewisse Bestätigung, als der für die Zeit vom 26. bis 28. August 1921 anberaumte Gegenbesuch des lettischen Außenministers Meierovics in Kowno unmittelbar bevorstand. In diesem Zusammenhang vertraute Purickis dem deutschen Gesandten an, er habe von der lettischen Regierung bereits die mündliche und schriftliche Versicherung erhalten, daß sie einer Einladung nach Warschau zur Fortsetzung der Konferenz von Helsinki nur dann folgen werde, wenn auch Litauen hinzugezogen würde ${ }^{106}$.

104 Note pour le Directeur „Mouvement des troupes en Pologne“, Paris, 30. VII. 1921, MAÉ, Russie, Vol. 298, Bl. 140.

105 Ber. Tgb. Nr. 6518 K. Nr. 519 v. Schönberg, Kowno, PA, IV Rd, Pol 3, Lit/Po, Bd. 2 (I. Serie).

106 Ber. Tgb. Nr. 6518 K. Nr. 519 v. Schönberg, Kowno, 24. VIII. 1921, PA, IV Rd, Pol 3, Lit/Po, Bd. 2 (I. Serie). 


\section{Randstaatenpolitik gegen Polen}

\section{Die Verschärfung der polnisch-lettischen Beziehungen}

Der Besuch Meierovics' in Kowno am 26. und 27. August 1921 bildete den Tiefpunkt der sich seit dem Frühjahr verschlechternden polnisch-lettischen Beziehungen, er schien die Ergebnisse der Konferenz von Helsinki wieder in Frage zu stellen. Das seit langem gehegte Mißtrauen der polnischen Regierung gegen die Randstaatenpläne Meierovics' endlud sich zunächst in scharfen Pressekommentaren. Zum Anlaß und Ausgangspunkt für ihre Polemik gegen den Besuch Meierovics' in Kowno nahm die polnische Presse Äußerungen des lettischen Ministerpräsidenten und Außenministers gegenüber litauischen Pressevertretern am 27. August 1921. Bei dieser Gelegenheit habe sich Meierovics ausdrücklich gegen eine weitere Konferenz der in Helsinki vertretenen vier Mächte ausgesprochen, solange der polnisch-litauische Konflikt nicht beigelegt sei. Lettland sei somit klar von der Linie seiner bisherigen Randstaatenpolitik abgerückt. Besonders eindeutig habe Meierovics außerdem seine antipolnische Haltung mit der Feststellung bekundet, daß Lettland und Polen nichts gemeinsames verbinde ${ }^{107}$. Die polnischen Pressekommentare entsprachen zwar im einzelnen nicht den Gedankengängen und Absichten des lettischen Außenministers, waren aber im Grundsatz auch nicht völlig unberechtigt. In dieser Form waren sie offensichtlich von der polnischen Regierung lanciert worden, um ihr die Gelegenheit zu bieten, ihre Sorgen und Befürchtungen, über die Entwicklung der Randstaatenpolitik zum Ausdruck zu bringen.

Meierovics war in Litauen herzlich aufgenommen und von der litauischen Regierung geradezu umworben worden. Indessen entsprach es durchaus der bisher von Meierovics gegenüber Litauen eingenommenen Haltung, wenn er nach der in der Randstaatenfrage erfolglosen Konferenz von Helsinki erneut Anstrengungen unternahm, Litauen wieder stärker in die baltischen Bündnispläne einzubeziehen. Dabei war es zweifellos unumgänglich, auch das schwierige litauisch-polnische Verhältnis in die politischen Gespräche mit der litauischen Regierung miteinzubeziehen. Wenn Meierovics auch zur Wilnafrage selbst keine öffentlichen Erklärungen abgab, so leistete er dennoch der litauischen Regierung insofern wertvolle außenpolitische Unterstützung gegen Polen, als er vor litauischen Pressevertretern aussprach, daß Lettland eine etwaige Besetzung Litauens durch Polen als Drohung ansehen und auf keinen Fall passiver Zuschauer und neutral bleiben würde. Vom deutschen Gesandten in Kowno auf diese Bemerkungen angesprochen, präzisierte Meierovics seinen Standpunkt in folgender Weise: „Polen gegenüber sei für Lettland große Vorsicht geboten, da man Beweise dafür habe, daß es im Falle einer Besetzung Litauens an der lettischen Grenze nicht Halt machen, sondern versuchen würde, sich in den Besitz von Libau, Dünaburg und Lettgallen zu setzen" 108 . Mochten die Erläuterungen einem deutschen Regie-

107 Ber. K. Nr. 712 v. Schoen, Warschau, 13. IX. 1921, PA, IV Rd, Pol 3, Lett/Po, Bd. 1 (Durchschlag).

108 Ber. Tgb. Nr. 6981 K. Nr. 544 v. Schönberg, Kowno, 2. IX. 1921, PA, IV Rd, Pol 3, Lett/Lit, Bd. 1. 
rungsvertreter gegenüber auch übertrieben sein, so zeigten sie doch angesichts der ungelösten polnisch-litauischen Streitigkeiten die wachsende Sorge der lettischen Regierung vor unberechenbaren politischen Schritten Polens.

Es war verständlich, daß die in der Öffentlichkeit gefallenen Äußerungen des lettischen Außenministers, in denen deutlich die Aufforderung an Polen steckte, die Souveränität Litauens zu respektieren und die Randstaatenbündnispläne nicht durch die Fortsetzung ihrer bisherigen Politik in der Wilnafrage zu erschweren, die polnische Regierung zu einer Reaktion veranlassen mußte. Wenige Tage nach Erscheinen der polnischen Pressekommentare ging Außenminister Skirmunt in einem Interview mit der polnischen Nachrichtenagentur PAT auf die Äußerungen Meierovics' in Kowno ein und erläuterte dabei zugleich die Haltung der polnischen Regierung in Fragen der baltischen Politik ${ }^{109}$. Während er die Beziehungen zu Estland und Finnland als nach wie vor herzlich und auf das gegenseitige Gefühl einer Interessengemeinschaft gestützt charakterisierte, wies er unter Hinweis auf die gefallenen Äußerungen des lettischen Außenministers auf die Verschlechterung der polnisch-lettischen Beziehungen hin. Sollten die in der polnischen Presse mitgeteilten Aussagen Meierovics' in Kowno dessen wirklichen Gedankengängen entsprechen, betonte Skirmunt, so müßte Polen seine bisherige baltische Politik überprüfen und gegebenenfalls revidieren. Obwohl die polnische Regierung ein freundschaftliches Verhältnis zu Lettland wünsche, sehe sie nur diese Möglichkeit, wenn jene Elemente in Lettland, die zu einem feindlichen, gegen Polen gerichteten politischen und militärischen Abkommen mit Litauen neigten, entscheidende Bedeutung erlangten ${ }^{110}$.

Skirmunts Ausführungen beschränkten sich nicht nur auf den Vorwurf einer antipolnischen Randstaatenpolitik der lettischen Regierung. Er ging zugleich auch auf die Entwicklung der bilateralen polnisch-lettischen Beziehungen ein und beschuldigte die lettische Regierung in diesem Zusammenhang einer polenfeindlichen Haltung, die dadurch deutlich zum Ausdruck komme, daß sie fortgesetzt die polnische Minderheit in Lettgallen schikaniere, deren Schulen schließe und in einer besonders böswilligen Weise die Agrarreform gegen polnische Staatsangehörige verwirkliche ${ }^{111}$. Auf den „sogenannten Dreibund“ eingehend, betonte Skirmunt Polens vollständige Gleichgültigkeit, solange es sich um eine rein wirtschaftliche Verständigung handele. Er schränkte seine Aussage jedoch insofern ein, als er die Zweckmäßigkeit eines wirtschaftlichen Bundes bezweifelte, der nur Staaten umfasse, die eine analoge Gestaltung der wirtschaftlichen Beziehungen besäßen und sich deshalb ,nichts anzubieten hätten und nichts austauschen könnten"112.

Die lettische Regierung antwortete auf die polnischen Angriffe mit behutsamen Gegenerklärungen, die den Anschein erweckten, als habe sie die polnischen Vorwürfe

109 Ber. K. Nr. 712 v. Schoen, Warschau, 13. IX. 1921, PA, IV Rd, Pol 3, Lett/Po, Bd. 1 (Durchschlag).

110 Ebenda.

111 Ebenda.

112 Ebenda. 
bereits erwartet. In einem langen und offensichtlich wohlvorbereiteten Kommuniqué wies die lettische Gesandtschaft in Warschau am 17. September 1921 zunächst den Vorwurf einer kulturellen und wirtschaftlichen Benachteiligung der polnischen Minderheit in Lettland zurück ${ }^{113}$. Mit dem Ziel, die Vorhaltungen der polnischen Regierung, Lettland betreibe eine polenfeindliche Randstaatenpolitik, zu entkräften, ging das Kommuniqué sodann ausführlich auf das lettisch-litauische Verhältnis ein. Mit besonderem Nachdruck erklärte die lettische Regierung, sie betrachte den Grundsatz der Selbstbestimmung der Völker als heilig und unverletzlich. Daher hätten auch die Bestrebungen des verwandten litauischen Volkes, seine staatliche Unabhängigkeit zu sichern, in Lettland verständliche Sympathien erzeugt, die ihren konkreten Ausdruck in der De-jure-Anerkennung Litauens durch die lettische Regierung gefunden hätte. Gleichzeitig bedaure Lettland indes das Fortdauern der polnisch-litauischen Mißhelligkeiten, welche den Abschluß eines Defensivbündnisses zwischen den baltischen Staaten und Polen verhinderten und verzögerten. In der Frage des verwickelten Streites selbst nehme die lettische Regierung freilich eine völlig neutrale Haltung ein. Die lettisch-litauische Annäherung habe daher einen rein wirtschaftlichen Charakter mit dem Ziel, den durch Krieg vernichteten Wohlstand wiederherzustellen. In diesem Sinne seien auch die Äußerungen des lettischen Ministerpräsidenten und Außenministers Meierovics in Kowno zu verstehen, der als Hauptgrund für die Bildung eines Dreibundes wirtschaftliche Überlegungen genannt habe ${ }^{114}$.

Geschickt die auf der Konferenz in Helsinki vereinbarten Grundsätze einer koordinierten Politik der beteiligten vier Mächte gegenüber Sowjetrußland betonend, stellte die lettische Regierung auch die politische Annäherung zwischen Lettland und Litauen in Zusammenhang mit den Beziehungen zu Sowjetrußland und brachte hiermit ihre Randstaatenkonzeption erneut zum Ausdruck. Sie unterstrich daher, daß eine gewisse politische Koordinierung mit Litauen darauf abziele, gemeinsam auf die Erfüllung der Friedensverträge durch Rußland zu achten. Dies dürfe von Polen nicht als Verletzung der lettischen Neutralität verstanden werden. Ebenso dürfe auch Litauen die politische Zusammenarbeit Lettlands mit Polen auf der Konferenz in Helsinki nicht als eine gegen Litauen gerichtete Stellungnahme der lettischen Regierung bewerten. Das Kommuniqué schloß mit der Feststellung, daß die Mehrzahl der polnischen Presseorgane über die Ausführungen Meierovics', ,in völlig entstellter Form“ berichtet hätte ${ }^{115}$.

Mit diesen Erklärungen gab sich die polnische Regierung jedoch keineswegs zufrieden. Sie erneuerte in einer Note an die lettische Regierung den Vorwurf einer antipolnischen Politik Lettlands und betonte dabei insbesondere die Verletzungen der Rechte der polnischen Minderheit in Lettland durch lettische Behörden ${ }^{116}$. Die polnischlettischen Beziehungen spitzten sich nunmehr noch weiter zu. Der abgewogenen Stel-

113 Ber. K. Nr. 730 v. Schoen, Warschau, 17. IX. 1921, PA, IV Rd, Pol 3, Lett/Po, Bd. 1.

114 Ebenda.

115 Ebenda.

116 Ber. Nr. Ko 219 v. Radowitz, Riga, 28. IX. 1921, ebenda. 
lungnahme der lettischen Regierung folgten jetzt heftige Reaktionen. In seiner Antwortnote an die polnische Regierung sprach Meierovics jedoch weniger die Probleme der Randstaatenpolitik an, sondern ging weitaus genauer und ausführlicher auf das Verhältnis Lettlands zu Polen ein. Entschieden wehrte er sich gegen den Vorwurf einer angeblichen Unterdrückung der polnischen Bevölkerung in Lettland und stellte fest, daß unverantwortliche Elemente der polnischen Bevölkerung sich dem lettischen Staat gegenüber feindlich verhielten, indem sie für einen Anschluß Lettgallens an Polen agitierten. Sie verbreiteten falsche Gerüchte über das bevorstehende Einrücken polnischer Truppen in dieses Gebiet und seien auch für die entstellten und tendenziösen polnischen Presseberichte verantwortlich ${ }^{117}$. Als Gegenstück zu dem erwähnten Interview Skirmunts gab Meierovics außerdem ausführliche Presseerklärungen ab, die am 21. bzw. 22. September 1921 in der gesamten Rigaer Presse erschienen. Darin bezeichnete er als eigentlichen Grund für die lettisch-polnischen Spannungen jetzt erstmals öffentlich die Tatsache, daß Polen die Grenze zwischen Lettland und Litauen noch nicht anerkannt habe, die von der lettischen Regierung als unumstößlich und endgültig angesehen werde ${ }^{118}$. Hierdurch fühlten sich Angehörige der polnischen Minderheit in Südlettgallen und im Illuxter Kreis ermuntert, gegen die Zugehörigkeit dieser Gebiete zu Lettland zu agitieren ${ }^{119}$. Voraussetzung für wirklich freundschaftliche Beziehungen zu Polen, die das lettische Volk aufrichtig wünsche, sei sowohl die Anerkennung der zwischen Lettland und Litauen festgelegten Grenze als auch die Respektierung der lettischen Agrargesetze ${ }^{120}$.

Auch in den folgenden Monaten hielt die polnisch-lettische Polemik unvermindert an. Als auf der Grundlage der lettischen Agrarreform ${ }^{121}$ mit Wirkung ab 1. Oktober 1921

117 Ber. Nr. Ko 219 v. Radowitz, Riga, 28. IX. 1921, PA, IV Rd, Pol 3, Lett/Po, Bd. 1.

118 Der endgültigen Festlegung der litauisch-lettischen Grenze waren zähe und langwierige Verhandlungen zwischen der lettischen und der litauischen Regierung vorausgegangen. Im wesentlichen handelte es sich um drei zwischen Litauen und Lettland umstrittene Fragen der Gebietszugehörigkeit. Am vordringlichsten war der Anspruch der litauischen Regierung auf das Gebiet von Polangen, wodurch Litauen Zugang zur Ostsee erhalten würde. Lettland strebte als Kompensation für die Abtretung Polangens nach dem Besitz des Eisenbahnknotenpunktes Mosheiki (lit. Mažeikiai), dessen Zugehörigkeit zu Litauen ein für das lettische Verkehrswesen überaus lästiges Hindernis darstellte, da hierdurch die Strecke Libau-Riga unterbrochen wurde. Eine weitere Divergenz lag schließlich in Bezug auf den Kreis Illuxt vor, auf den Lettland als wichtiges Ernährungsgebiet für Dünaburg Anspruch erhob. Ber. K. Nr. 112 v. Wever, Riga, 29. XII. 1920, PA, IV Rd, Pol 3, Lett/ Lit, Bd. 1.

119 Die Agitation der Polen im Illuxter Kreis war darauf zurückzuführen, daß sie sich mit der Übertragung dieses Gebietes an Lettland nicht abfinden wollten. Solange die Frage der Zugehörigkeit des Illuxter Kreises zum lettischen Staatsgebiet nicht entschieden war, solange konnten die dort lebenden Polen darauf hoffen, daß das Gebiet auf dem Umwege über eine polnisch-litauische Konföderation doch noch unter polnischen Einfluß geraten würde.

120 Ber. Nr. Ko 219 v. Radowitz, Riga, 28. IX. 1921, PA, IV Rd, Pol 3, Lett/Po, Bd. 1.

121 Die Agrarreform in Lettland beruhte auf einem Gesetz, das die konstituierende Versammlung am 16. IX. 1920 verabschiedet hatte. Danach unterlagen 1300 große Güter mit zusammen über 3 Millionen Hektar Land oder 48 Prozent der Gesamtfläche Lettlands der Enteignung, die entschädigungslos vollzogen wurde. Den im Lande verbliebenen ehemaligen Besitzern wurde ein Restgut 
in Lettland alle in- und ausländischen Gutsbesitzer, die mehr als 100 Hektar Land besaßen, entschädigungslos enteignet wurden, verschärften sich die Spannungen zwischen Lettland und Polen weiter. Mit wachsender Erbitterung protestierte die polnische Regierung gegen die Enteignungen polnischer Staatsbürger in Lettgallen und wandte sich mit einer Beschwerdenote an den Völkerbund, der daraufhin von Lettland Aufklärungen forderte ${ }^{122}$. $\mathrm{Zu}$ einer Abmilderung oder Modifizierung der lettischen Agrargesetze führte aber auch dieser Schritt nicht. In Polen setzte zur gleichen Zeit eine scharfe Pressekampagne gegen das Vorgehen der lettischen Behörden ein. Besonders nachdrücklich verlangten die nationaldemokratischen Presseorgane wiederholt die Rückgabe der konfiszierten Güter oder zumindest angemessene Entschädigungszahlungen. Die in der bisherigen Weise durchgeführten Enteignungen prangerten sie als den Versuch an, das polnische Element aus Lettland zu vertreiben und zu entnationalisieren ${ }^{123}$.

$\mathrm{Zu}$ dieser Frage nahm lediglich der sozialistische „Robotnik“ eine abweichende Haltung ein. Er setzte sich dafür ein, die lettischen Agrargesetze als souveräne Entscheidungen der lettischen Regierung zu respektieren und nicht zum Gegenstand polnischlettischer Auseinandersetzungen zu machen. Seine ausdrücklichen Warnungen vor einer weiteren Verschlechterung der polnisch-lettischen Beziehungen fanden bei der Regierung und der öffentlichen Meinung Polens allerdings kaum Verständnis, obwohl sie den außenpolitischen Interessen des polnischen Staates in besonderer Weise Rechnung trugen ${ }^{124}$. Bereits Ende 1920 hatte das sozialistische Parteiorgan seine Stellungnahme ausführlich begründet. Unter Hinweis auf Polens gefährliche außenpolitische Lage hatte es daran erinnert, daß freundschaftliche Beziehungen Polens zu Lettland lebenswichtig seien, da Lettland entweder eine Scheidewand zwischen Deutschland und Rußland oder aber ein Glied in der Polen erdrosselnden deutsch-russischen Kette bilden könnte. Aus diesem Grunde dürften gutnachbarliche Beziehungen zu Lettland nicht mit der Forderung nach Ausnahmerechten für die polnische Bevölkerung gefährdet werden, zumal die Polen in Lettgallen nur eine kleine Minderheit seien, die dort höchstens 12 Prozent der Bevölkerung oder 50000 Menschen ausmachten ${ }^{125}$.

bis zu höchstens 50 Hektar belassen, während alle außer Landes gegangenen Großgrundbesitzer ohne jede Entschädigung blieben. Die enteigneten Güter wurden zwecks Begründung neuer Kleinwirtschaften, deren wirtschaftliche Nutzfläche 22 Hektar nicht übersteigen durfte, unter die Landlosen und Kleinbauern aufgeteilt.

122 Ber. K. Nr. 94 v. Schoen, Warschau, 28. I. 1922, PA, IV Rd, Pol 3, Lett/Po, Bd. 1.

123 Ber. K. Nr. 913 und K. Nr. 55 v. Schoen, Warschau, 26. X. 1921 bzw. 20. I. 1922, ebenda.

124 Robotnik v. 8. I. 1922.

125 Robotnik v. 30. XI. 1920. - Nach den Angaben der lettischen Volkszählung von 1930 lebten in Lettland 1900045 Personen. Die Polen bildeten mit 59374 Personen oder 3,1\% der Gesamtbevölkerung erst die viertgrößte Minderheit nach den Russen (201779 oder 10,6\%), Juden (94388 oder $5 \%$ ) und Deutschen (69855 oder 3,7\%). Vgl. Leon Wasilewski, Skład narodowościowy państw europejskich, Warschau 1933, S. 61f. Von polnischer Seite wurden die Zahlenangaben über den polnischen Bevölkerungsanteil in Lettland als zu niedrig in Zweifel gezogen. Vgl. Witold Sworakowski, Liczba i rozmieszczenie Polaków w Łotwie, in: Sprawy Narodowościowe 8 (1934), S. 151-180. 
Mit ihrer Kritik an der lettischen Agrargesetzgebung steigerte die nationaldemokratische Presse auch ihre Vorwürfe gegen die Außenpolitik Meierovics'. Der „Kurjer Warszawski" begnügte sich nicht mit der Wiederholung, Lettland habe mit Litauen ein gegen Polen gerichtetes Bündnis abgeschlossen, sondern griff die lettische Regierung jetzt auch wegen ihrer weitgehenden Handelsbeziehungen zu Deutschland und Sowjetrußland an, die er als Indiz für deren polenfeindliche Bestrebungen wertete. Auf die Bündnispläne der Randstaaten eingehend warf das Blatt Meierovics schließlich vor, er suche immer deutlicher einen Bund aus Litauen, Lettland, Estland und Finnland zu gründen, um dann Polen im Namen dieser vier Staaten die Bedingungen zu diktieren, unter denen es dann zu dem Bunde hinzugezogen werden könne ${ }^{126}$.

Auf die polnischen Presseangriffe antwortete die lettische Gesandtschaft in Warschau wiederum mit einer ausführlichen Gegendarstellung. Sie verbat sich in der Agrarfrage jede Einmischung in die inneren Angelegenheiten Lettlands, begründete den wachsenden Handelsverkehr mit Deutschland und Sowjetrußland mit Lettlands geographischer Lage und beteuerte erneut die lettische Neutralität im Wilnakonflikt. Gerade diese neutrale Haltung verbiete der lettischen Regierung eine engere politische Annäherung an Litauen oder Polen ${ }^{127}$. Als unverständlich bezeichnete die lettische Vertretung ferner das Mißbehagen der polnischen Presse gegen eine Annäherung Lettlands an Estland und Finnland, aus dem man lediglich schließen könne, daß Polen selbst eine engere Verbindung zwischen Lettland, Estland und Finnland nicht wünsche. In Anspielung auf die während der Konferenz in Helsinki verfolgte Politik Polens in der Randstaatenfrage fügte die lettische Gesandtschaft die kritische Bemerkung hinzu, Polen stelle sich wohl deshalb einer solchen Annäherung entgegen, weil es von einem baltischen Bund nicht das erreichen könnte, was es von einzelnen baltischen Staaten zu erlangen sich verspreche ${ }^{128}$.

\section{Die zunehmende Isolierung Polens}

Die sich steigernde Kritik der polnischen Presse an der Außenpolitik von Meierovics verdeutlichte die Furcht der polnischen Regierung, in der Randstaatenfrage zunehmend in die Rolle eines passiven Zuschauers gedrängt zu werden. Nicht nur die anhaltenden lettisch-polnischen Spannungen und der unverändert harte Gegensatz zwischen Polen und Litauen in der Wilnafrage beeinträchtigten die polnischen Randstaatenpläne im Herbst 1921. Die gleichzeitige gefährliche Zuspitzung der polnischsowjetischen Beziehungen ${ }^{129}$ sowie die massiven Drohungen der Sowjetregierung gegen alle polnisch-baltischen Bündnisbestrebungen vergrößerten jetzt die Schwierigkeiten der baltischen Politik Polens zusätzlich.

Die Sowjetregierung suchte nunmehr nicht nur die Furcht vor einem Zusammengehen der baltischen Staaten mit Polen zu steigern, sondern auch gleichzeitig Litauen für den

126 Kurjer Warszawski v. 13. XI. 1921.

127 Ber. K. Nr. 1031 v. Benndorf, Warschau, 21. XI. 1921, PA, IV Rd, Pol 3, Lett/Po, Bd. 1 (Durchschlag).

128 Ebenda.

129 Vgl. S. $81 \mathrm{ff}$. 
Fall einer kriegerischen Auseinandersetzung mit Polen als Verbündeten zu gewinnen. Im Auftrag seiner Regierung fragte der Sowjetgesandte in Kowno, Aralov, Außenminister Purickis gegen Ende September 1921, welche Haltung Litauen einnehmen werde, falls es erneut zu einem polnisch-sowjetischen Kriege kommen werde. Um der litauischen Regierung die Antwort zu erleichtern, erklärte Aralov gleichzeitig, daß sich ein Krieg mit Polen aller Wahrscheinlichkeit nach nicht werde vermeiden lassen und daß in einem solchen Falle die weitere Anwesenheit Żeligowskis in Wilna von der Sowjetregierung nicht länger geduldet würde. Trotz der deutlichen Avancen, die Aralov der litauischen Regierung mit diesen Äußerungen im Hinblick auf eine Wiedergewinnung des Wilnagebietes machte, erklärte Purickis sofort die strikte Neutralität seines Landes für den Fall eines polnisch-sowjetischen Krieges ${ }^{130}$. Purickis' sofortige Ablehnung des vorsichtig vorgetragenen sowjetischen Angebotes zeigte, daß die litauische Regierung zwar diplomatische Unterstützung der Sowjetregierung in der Wilnafrage gegen Polen durchaus zu schätzen wußte ${ }^{131}$, aber die mögliche Wiedergewinnung Wilnas für Litauen nicht mit dem Preis einer litauisch-sowjetischen Waffenbrüderschaft bezahlen wollte. Eine aktive Zusammenarbeit zwischen Litauen und Sowjetrußland über den diplomatischen Rahmen hinaus mußte für Litauen jede engere Verbindung mit den übrigen baltischen Staaten erschweren und konnte möglicherweise auch für die eigene Unabhängigkeit gefährlich werden.

Die schwierige Lage Polens im Herbst 1921 suchte vor allem auch Meierovics auszunutzen, um erneut Tendenzen zu einem engeren Zusammenschluß der baltischen Republiken ohne Polen zu fördern. Der lettische Ministerpräsident und Außenminister beschränkte seine Bemühungen dabei indes nicht auf ein Bündnis Lettlands mit Estland und Finnland, wie die lettische Gesandtschaft in Warschau glaubhaft machen wollte ${ }^{132}$, sondern beabsichtigte auch Litauen in diese Kombination miteinzubeziehen.

Für den Gedanken eines Bündnisses zwischen Finnland, Estland und Lettland war bisher lediglich der estnische Gesandte in Riga, Aleksander Hellat ${ }^{133}$, ernsthaft eingetreten. Noch im Februar 1921 hatte sich Hellat für ein die baltischen Staaten, Polen und Finnland umfassendes Bündnis energisch eingesetzt und eine Randstaatenverbindung ohne eine Beteiligung Polens für unmöglich erklärt ${ }^{134}$. Er war jedoch sehr bald zu der Überzeugung gelangt, daß dieser Konzeption vorerst die reale Grundlage fehlte.

130 Tel. des litauischen Außenministeriums an die litauische diplomatische Vertretung in Paris vom 28. IX. 1921. Dieses Telegramm wurde von französischen Dienststellen dechiffriert. Eine französische Übersetzung befindet sich in den Akten des Quai d'Orsay, MAÉ, Russie, Vol. 298, Bl. 166. Das französische Außenministerium konnte sich von der Echtheit des Telegramms überzeugen, als der englische Botschafter in Paris, Lord Hardinge, dem Generalsekretär des Quai d'Orsay, Berthelot, am 30. IX. 1921 die gleiche Information mitteilte, die das Foreign Office direkt aus Kowno erhalten hatte (Visite de l'Ambassadeur d'Angleterre, „Lithuanie, Pologne et Bolchéviks“, Paris, 30. IX. 1921, ebenda, Bl. 175).

131 Vgl. oben, S. $105 \mathrm{f}$.

132 Vgl. oben, S. 128.

133 Vgl. Biographischer Anhang.

134 Arumjae, S. 104. 
In seiner Auffassung wurde er durch eine dreiwöchige Informationsreise nach Warschau bestärkt, die er im Frühjahr 1921 unternommen hatte. Über seine Eindrücke, die er während seines Aufenthaltes in Polen gewonnen hatte, berichtete er danach eingehend dem estnischen Außenministerium. Er bezeichnete dabei bemerkenswerterweise nicht den polnisch-litauischen Wilnakonflikt als erstes und wichtigstes Hindernis für die Konzeption eines polnisch-baltisch-finnischen Staatenbundes, sondern die politische Kräfteverteilung in Polen selbst. Mit ausdrücklichem Bedauern stellte er fest, daß die nationaldemokratische Richtung in Polen den entscheidenden Einfluß auf die Regierungspolitik ausübe. Die nationaldemokratischen Regierungskreise aber zeigten gerade für die baltische Frage nur wenig Interesse, sie konzentrierten vielmehr ihre Aufmerksamkeit auf andere Probleme der polnischen Außenpolitik. Dagegen sei die außenpolitische Richtung in Polen, die sich eingehend mit der Randstaatenfrage beschäftige, schwach und werde sich nicht durchsetzen können ${ }^{135}$. Aus diesen Úberlegungen heraus entwickelte Hellat das Projekt eines finnisch-estnisch-lettischen Bündnisses, das er als Kern eines Randstaatenbündnisses für realisierbar hielt. Er verteidigte diesen Plan auch gegenüber seinem polnischen Kollegen Kamieniecki ${ }^{136}$, konnte aber, da sich die finnische Regierung selbst gegenüber bilateralen estnisch-finnischen Bündnisprojekten weiterhin ablehnend verhielt ${ }^{137}$, seine Vorstellungen innerhalb der eigenen Regierung nicht durchsetzen.

Wenn Meierovics das Projekt Hellats im Herbst 1921 erstmals durch die lettische Gesandtschaft in Warschau öffentlich aufgreifen ließ, so verfolgte er damit offensichtlich rein taktische Ziele. Zum einen wollte er vermutlich Hellats Einfluß in Reval stärken, in der Absicht, jeden, wenn auch schwachen Anhaltspunkt für eine estnische Randstaatenpolitik unter Ausschluß Polens zu fördern. Zum anderen ermöglichte ihm der Plan Hellats auch, eine eigene und klare Stellungnahme zugunsten Litauens und gegen Polen zu vermeiden, die den Widerspruch der estnischen Regierung erregen konnte. Sein tatsächliches Ziel aber war trotz aller Dementis und diplomatischen Ablenkungsmanöver der lettischen Regierung eindeutig die Wiederbelebung eines kleinen, Estland, Lettland und Litauen umfassenden Randstaatenbundes, dem sich Finnland unmittelbar anschließen sollte ${ }^{138}$. Völlig aussichtslos schien eine baltischfinnische Allianz ohne Beteiligung Polens nicht zu sein. Mit der Hinzuziehung Finnlands suchte Meierovics dem Drängen Estlands nach einem Bündnis mit Finnland Rechnung zu tragen und hoffte dadurch gleichzeitig die Vorbehalte der estnischen Regierung gegen die Nichtbeteiligung Polens an einer Randstaatenföderation überwinden zu können. Trotz aller Bemühungen der lettischen Diplomatie ließ sich die estnische Regierung jedoch nicht von ihrer Forderung abbringen, Polen in einen Randstaatenbund einzubeziehen ${ }^{139}$, während die litauische Regierung nach wie vor

\footnotetext{
135 Arumjaè, S. 107.

136 Skrzypek, Związek bałtycki, S. 109, Anm. 170.

137 Vgl. oben, S. $109 \mathrm{f}$.

138 Skrzypek, Związek bałtycki, S. 135.

139 Arumjaè, S. 131.
} 
gerade den Ausschluß Polens aus jeder Randstaatenverbindung zur Voraussetzung ihrer eigenen Beteiligung machte.

Im Gegensatz zur estnischen hatte die finnische Regierung die Möglichkeit erkennen lassen, den lettischen Randstaatenplänen zu folgen. Hierfür waren mehrere Gründe maßgebend. Anstrengungen der finnischen Außenpolitik, sich nach der offiziellen Beilegung der Åland-Frage Schweden freundschaftlich anzunähern, waren erneut an der neutralistischen Haltung der Regierung in Stockholm gescheitert. Da auf der Konferenz in Helsinki keine Fortschritte in der Randstaatenfrage erzielt wurden, vertrat die finnische Regierung die Auffassung, die Bildung eines Randstaatenbundes unter Einschluß Polens werde lange Zeit keine feste Gestalt annehmen. Immer stärker setzte sich daher in der finnischen Regierung die Úberzeugung durch, daß die bisherige Außenpolitik Holstis zu einer drohenden außenpolitischen Isolierung Finnlands innerhalb der nordischen Staaten wie der baltischen Randstaaten geführt habe ${ }^{140}$. Einen Ausweg aus dieser schwierigen Lage sah die finnische Regierung nun in einer vorläufigen Annäherung an die baltischen Staaten, solange die Spannungen zwischen Polen auf der einen Seite und Lettland wie Litauen auf der anderen Seite anhielten. Dabei war sich die finnische Regierung durchaus darüber im klaren, daß eine engere finnisch-baltische Zusammenarbeit im Hinblick auf eine Sicherung vor Rußland nur einen unzureichenden Ersatz für ein Randstaatenbündnis unter Einschluß Polens darstellte. Um von vornherein jede antipolnische Spitze, wie sie in der Politik Litauens und Lettlands zum Ausdruck kam, zu vermeiden, begegnete die finnische Regierung daher dem lettischen Werben mit Zurückhaltung, jedoch nicht ohne Wohlwollen. Ohne sich über die Ziele ihrer Randstaatenpolitik eindeutig zu äußern, deutete sie verschiedentlich ihre weiterhin bestehenden Sympathien für eine Teilnahme Polens an einer Randstaatenverbindung an ${ }^{141}$.

Wenn die finnische Regierung ihren Wunsch nach Einbeziehung Polens in eine Randstaatenföderation nicht deutlicher zum Ausdruck brachte, so lag dies nur zum Teil daran, daß sie mit einer offeneren Parteinahme für Polen die Weiterentwicklung der Randstaatenpläne zu erschweren glaubte, die sie grundsätzlich zu fördern bemüht war. Rücksichtnahme auf Deutschland ${ }^{142}$ sowie innenpolitische Gründe bestärkten sie in dieser Haltung ebenfalls. Immer heftiger sprachen sich die numerisch starken Sozialdemokraten im finnischen Reichstag ${ }^{143}$, auf deren konstruktive parlamentari-

140 Ber. Nr. 899 v. Küchler, Helsinki, 21. X. 1921, PA, IV Nd, Finnland, Pol 1, Bd. 1.

141 Wie vorsichtig und abwartend die finnische Regierung auf die lettischen Randstaatenpläne einging, zeigten Äußerungen des Vizepräsidenten des finnischen Reichstages und einflußreichen Mitgliedes der regierenden Fortschrittspartei, Dr. Mantere, während eines Informationsbesuches in Riga im Oktober 1921. Den Fragen lettischer Pressevertreter, welche Haltung Finnland in der Randstaatenfrage einnehme, wich er mit der Bemerkung aus, die Frage nach der Bildung eines Vier- oder Fünfstaatenbundes sei noch nicht in dem Maße in der finnischen Öffentlichkeit behandelt worden, daß Finnland schon jetzt einen präzisierten Standpunkt einzunehmen imstande sei. Ber. Ko 238 v. Radowitz, Riga, 19. X. 1921, PA, IV Nd, Finnland, Pol 1, Bd. 1.

142 Vgl. oben, S. 118.

143 Von insgesamt 200 Abgeordneten des finnischen Reichstages stellten in den Jahren 1919-1922 die Sozialdemokraten mit 80 Abgeordneten die stärkste Fraktion. Die Regierungskoalition ver- 
sche Mitarbeit sich die Politik der finnischen Minderheitsregierung bisher im wesentlichen gestützt hatte, gegen jede außenpolitische Zusammenarbeit mit Polen aus. Die bereits vor und während der Konferenz in Helsinki deutlich gewordene ablehnende Einstellung der finnischen Sozialdemokraten gegenüber der Außenpolitik Polens hatte sich angesichts der Verschärfung des polnisch-sowjetischen Verhältnisses im Herbst 1921 noch weiter verhärtet.

Die baltisch-finnischen Bündnispläne Meierovics' gewannen vorübergehende Bedeutung, obwohl die gegensätzlichen Standpunkte Estlands und Litauens gegenüber Polen offizielle Regierungsverhandlungen über die Bildung eines die baltischen Staaten und Finnland umfassenden Randstaatenbundes nicht zuließen. Auf einer Konferenz der sozialdemokratischen Parteien Finnlands, Estlands, Lettlands und Litauens, deren Vertreter sich am 17. und 18. Oktober 1921 in Riga versammelten, wurde die Randstaatenbündnisfrage ausführlich erörtert. Die lettischen Sozialdemokraten unterstützten als Koalitionspartner des lettischen Bauernbundes die Konzeption von Meierovics. In der Frage, ob Polen in einen Randstaatenbund mit einbezogen werden sollte, stellten sich zwischen den Delegierten Estlands und Litauens die größten Meinungsverschiedenheiten heraus. Bemerkenswerterweise vertraten die Sozialdemokraten Litauens und Estlands in der Randstaatenfrage die Politik ihrer jeweiligen Regierungen, obgleich sie in ihren Ländern zu den Oppositionsparteien gehörten. Die litauischen Vertreter brachten mit Unterstützung der lettischen Delegierten schließlich eine Resolution ein, in der nicht nur eine engere Zusammenarbeit zwischen Finnland, Estland, Lettland und Litauen, sondern darüber hinaus auch eine Annäherung dieser vier Staaten an Sowjetrußland als wünschenswert bezeichnet wurde ${ }^{144}$. Der antipolnische Charakter dieser Resolution wurde außerdem mit der Feststellung betont, daß die auf der Konferenz vertretenen Parteien sich einem gemeinsamen außenpolitischen Kurs ihrer Länder mit Polen widersetzen sollten. Insbesondere wurde ein Militärbündnis irgendeines der baltischen Staaten oder Finnlands mit Polen für unzulässig erklärt. Die Beschlüsse trafen auf entschiedene Vorbehalte der estnischen Vertreter ${ }^{145}$, wurden aber gegen ihren Widerstand durchgesetzt, da auch die finnischen Delegierten ihnen zustimmten ${ }^{146}$.

\section{Randstaatenpolitik und Wirtschaftsinteressen}

Die Resolutionen der finnischen und baltischen Sozialdemokraten verschafften in der außenpolitischen Diskussion ihrer Länder dem Gedanken einer Randstaatenverbindung unter Ausschluß Polens zweifellos eine stärkere Geltung als zuvor. Auf Regierungsebene entsprachen den sozialdemokratischen Beschlüssen gleichzeitig einset-

fügte über 68 Mandate, von denen 42 auf die Agrarpartei und 26 auf die Fortschrittspartei entfielen. 28 Abgeordnete gehörten der Partei der nationalen Konsolidierung (Sammlungspartei) an und 22 Abgeordnete vertraten die Schwedische Volkspartei. Vgl. Jaako Nousiainen, Finlands politiska partier, Stockholm 1960, S. 24.

144 Skrzypek, Związek baltycki, S. 134 f.

145 Arumjae, S. 132.

146 Ebenda; Kalela, S. 64. 
zende Bemühungen Meierovics', seine Konzeption durch eine engere wirtschaftliche Verflechtung der baltischen Staaten und Finnlands untereinander voranzutreiben. Eine gegenseitige wirtschaftliche Annäherung lag durchaus im Interesse aller baltischen Staaten einschließlich Finnlands. Die lettische Regierung nutzte diese Einmütigkeit und lud Vertreter Finnlands, Estlands und Litauens zu einer Wirtschaftskonferenz für die Zeit vom 12. bis 15. September 1921 nach Riga ein. Wenn es auf dieser Konferenz auch hauptsächlich um technisch-wirtschaftliche Fragen, wie Vereinheitlichung der Zolltarife und Regelung des Flachs- und Holzhandels untereinander ging $^{147}$, so bestand doch kein Zweifel, daß die wirtschaftlichen Besprechungen auch politisch den Gedanken eines engeren Zusammenschlusses der beteiligten Konferenzteilnehmer förderten ${ }^{148}$.

Die beginnende Ausgestaltung der wirtschaftlichen Beziehungen zwischen den baltischen Staaten und Finnland war somit ein deutliches Anzeichen für den schwindenden Einfluß Polens auf die Randstaatenpolitik. Die sowjetische Regierung nutzte nun ihrerseits die sich abzeichnende Außenseiterstellung Polens und drängte noch während der baltisch-finnischen Wirtschaftsbesprechungen auf die Einberufung einer Wirtschaftskonferenz, an der neben Vertretern Sowjetrußlands Beauftragte der Regierungen Finnlands, Estlands, Lettlands und Litauens teilnehmen sollten ${ }^{149}$. Entsprechenden Vorschlägen der Sowjetregierung vom Juli 1921 waren die Regierungen Finnlands und der baltischen Staaten bisher mit Zurückhaltung begegnet. Mehrfach waren sie mit der offiziellen Begründung, eine finnisch-baltisch-sowjetische Wirtschaftskonferenz erfordere eine sehr gründliche Vorbereitung, allen konkreten Terminvorschlägen ausgewichen ${ }^{150}$. Ihr Hinweis auf „gründliche Vorbereitungen“ beinhaltete freilich weit mehr als nur die Regelung technisch-organisatorischer Fragen. Bevor Finnland und die baltischen Staaten in gemeinsame Wirtschaftsverhandlungen mit Sowjetrußland eintreten wollten, suchten sie zunächst selbst ihre wirtschaftlichen Beziehungen untereinander enger zu gestalten und auch ihre Verhandlungsführung mit der Sowjetregierung aufeinander abzustimmen. Die Gegensätzlichkeiten in der Randstaatenpolitik hatten bisher die Ausarbeitung verbindlicher Richtlinien für gemeinsame Wirtschaftsverhandlungen mit der sowjetischen Regierung erschwert und verzögert.

Die stärksten Bedenken hatte die estnische Regierung gegen die Aufnahme von Wirtschaftsverhandlungen zwischen den baltischen Staaten, Finnland und Sowjetrußland

147 Einzelheiten zu Art und Umfang des finnisch-baltischen Handelsverkehrs seit 1921 bei Erkki Pihkala, Der baltische Handel Finnlands, in: JbbGOE 23 (1975), S. 15-19. Das Handelsvolumen der baltischen Staaten untereinander war gering. An Lettlands gesamtem Import- und Exportwert hatte z. B. Estland im Jahre 1920 und im Jahre 1925 nur einen Anteil von 2,6\%, Litauen 1920 lediglich $0,3 \%$ und 1925 3,9\%. Estlands und Litauens Anteile fielen bis zum Jahre 1938 auf $0,8 \%$ bzw. 1,2\%. Sven Swedberg, Der Außenhandel der selbständigen baltischen Staaten in den Jahren 1918-1938, in: Mare Balticum, 1 (1968), S. 64.

148 Ber. Nr. A-1785 v. Radowitz, Riga, 19. IX. 1921, PA, IV Rd, Wi 7, Bd. 1.

149 Ebenda.

150 Ber. Ko Nr. 249 v. Rudolph, Riga, 8. XI. 1921, PA, IV Rd, Wi 7, Bd. 1. 
erhoben, weil sie hierdurch die mit Polen auf der Konferenz in Helsinki vereinbarte außenpolitische Solidarität gegenüber Sowjetrußland gefährdet sah. Ihre Besorgnisse schienen in den Hintergrund zu treten, als die nunmehr abgeschlossenen baltischfinnischen Wirtschaftsverhandlungen günstige Voraussetzungen für die gemeinsame Annahme des sowjetischen Vorschlages schufen. Ausschlaggebend für die Überwindung ihrer Bedenken aber wurde das außerordentliche Interesse der estnischen Regierung am wachsenden Transithandel Sowjetrußlands.

In den ersten 9 Monaten des Jahres 1921 wurden Handelsgüter im Werte von insgesamt 61,38 Millionen Goldrubel - das waren 45 Prozent des Gesamtwertes aller sowjetischen Importe innerhalb desselben Zeitraumes - durch Finnland und die baltischen Staaten nach Sowjetrußland transferiert ${ }^{151}$. Hiervon beförderte allein Estland Güter im Werte von 55,26 Millionen Goldrubel oder 90 Prozent des Wertes aller Waren, die im Transitverkehr durch die baltischen Staaten und Finnland von Sowjetrußland bezogen wurden. Mit weitem Abstand folgte an zweiter Stelle Lettland, durch dessen Transithäfen Waren im Werte von 5 Millionen Goldrubel (스 8,14 Prozent) nach Sowjetrußland weiterbefördert wurden. Finnland und Litauen schließlich waren wegen ihrer ungünstigen geographischen Lage an den sowjetischen Importen lediglich mit Wertanteilen von 0,64 (스 1,04 Prozent) bzw. 0,47 (스 0,7 Prozent) Millionen Goldrubel beteiligt ${ }^{152}$. Die unterschiedlichen Anteile Estlands und Lettlands erklärten sich daraus, daß Estland in seiner Entwicklung als Transithandelsland Lettland um etwa ein Jahr voraus war. Als sich der Transithandel bemerkbar machte, befanden sich Sowjetrußland mit Lettland und Lettland mit Deutschland noch im Kriegszustand. Aus diesem Grunde war die Haupthandelsstraße bisher auf den Umweg über Estland bzw. Reval angewiesen, solange die bequemeren und geräumigeren lettischen Häfen Riga und Libau versperrt blieben. Der nach Abschluß des lettischsowjetischen Friedensvertrages einsetzende Transithandel erreichte im April 1921 seinen Höhepunkt, flaute im Juni und Juli stark ab und hörte nach dem Zwischenfall aus Anlaß der Aburteilung lettischer Kommunisten ${ }^{153}$ fast vollständig auf. Wesentliche Anteile Rigas und Libaus am russischen Transithandelsverkehr gingen hiermit zusätzlich auf Reval über. Nach Beilegung dieses Zwischenfalls wurde indes der Wunsch der lettischen wie der sowjetischen Regierung wieder stärker, den russischen Transitverkehr in größerem Umfange auch durch lettische Häfen zu leiten ${ }^{154}$.

Ungünstige wirtschaftliche Auswirkungen der sowjetischen Transithandelspolitik auf Reval konnte die estnische Regierung nur dadurch aufzuhalten versuchen, daß sie sich dem sowjetischen Vorschlag einer gemeinsamen baltisch-finnisch-sowjetischen Wirtschaftskonferenz nicht länger entzog. Die geschickte Ausnutzung der Wirtschaftskonkurrenz zwischen Lettland und Estland im Transithandel erwies sich somit für die Sowjetregierung als geeigneter Weg, die Zustimmung der baltischen Staaten und Finnlands, das ebenfalls an einer Steigerung des sowjetischen Transithandelsverkehrs in-

151 DVP IV, S. 744.

152 DVP IV, S. 743.

153 Vgl. oben, S. 106, Anm. 34.

154 Ber. Nr. Wi-1585 v. Radowitz, Riga, 6. IX. 1921, PA, IV Ru, Handel 11, Ru/Dt, Bd. 4. 
teressiert war, zu dem genannten Vorschlag zu erhalten. Unter diesen Voraussetzungen einigten sich die Vertreter Finnlands, Estlands, Lettlands und Litauens, das umfangreiche Programm der Sowjetregierung, in dem die Ausarbeitung einer Reihe von Regelungen und Erleichterungen im Transit- und Handelsverkehr vorgeschlagen wurde, als Arbeitsgrundlage anzuerkennen und die Konferenz für die Zeit vom 28. bis 31. Oktober 1921 nach Riga einzuberufen ${ }^{155}$.

Die Ergebnisse dieser viertägigen Wirtschaftskonferenz, deren Bedeutung mit der vorübergehenden Teilnahme der Außenminister Piip und Purickis an den Verhandlungen noch unterstrichen wurde ${ }^{156}$, bestätigten das Interesse der baltischen Staaten und Finnlands am Ausbau ihres Wirtschaftsverkehrs mit Sowjetrußland. Die Konferenzergebnisse wurden in zahlreiche Resolutionen gefaßt. Diese Resolutionen, die von sieben Kommissionen ausgearbeitet wurden, stellten keine endgültigen Beschlüsse dar, sondern legten Richtlinien für einzelne Verbesserungen im Transit-, Transport- und Finanzverkehr zwischen den an der Konferenz beteiligten Regierungen fest ${ }^{157}$. Ein konkreter Erfolg der Konferenz war zweifellos der Beschluß, ein „Ständiges Wirtschaftsbüro" in Riga einzurichten, das - aus je einem Vertreter der baltischen Staaten, Finnlands und Sowjetrußlands bestehend - für die weitere Durchführung der vorgezeichneten Richtlinien zuständig sein sollte ${ }^{158}$. Aufgrund dieser Empfehlungen fand im April 1922 eine Eisenbahnkonferenz statt, an der Vertreter Sowjetrußlands, Litauens, Lettlands und auch Deutschlands teilnahmen. Auch auf weiteren Gebieten zog die Wirtschaftskonferenz praktische Maßnahmen nach sich. Im März 1922 wurden auf einer baltisch-finnisch-sowjetischen Konferenz Richtlinien für eine gemeinsame Bekämpfung von Epidemien ausgearbeitet und am 24. Juni 1922 eine lettisch-sowjetische Sanitätskonvention unterzeichnet ${ }^{159}$. Die Mehrzahl der Resolutionen wurde jedoch nicht verwirklicht. Als Hindernisse erwiesen sich erneute politische Spannungen zwischen Sowjetrußland einerseits und den baltischen Staaten Estland und Lettland andererseits im Sommer 1922. Diese Spannungen waren zum einen wiederum auf eine stärkere außenpolitische Anlehnung der beiden Länder an Polen zurückzuführen ${ }^{160}$, zum anderen aber auch durch eine Zunahme von Zwischenfällen in den sowjetischestnischen bzw. sowjetisch-lettischen Beziehungen bedingt ${ }^{161}$. Die zwischenstaatli-

155 Ber. Nr. A-1785 v. Radowitz, Riga, 19. IX. 1921, PA, IV Rd, Wi 7, Bd. 1.

156 Ber. Ko Nr. 242 v. Rudolph, Riga, 26. X. 1921, ebenda.

157 Rezoljucii Ėkonomičeskoj konferencii Pribaltijskich gosudarstv i RSFSR, 31. X. 1921, DVP IV, S. 456-462; vgl. auch Sobolevitch, S. 110.

158 Rezoljucii Ėkonomičeskoj konferencii Pribaltijskich gosudarstv i RSFSR, 31. X. 1921, DVP IV, S. 460; Vygodskij, S. $172 \mathrm{f}$.

159 Latvian-Russian Relations. Documents, Washington 1944, S. 114-123.

160 Vgl. Kumaniecki, Po traktacie ryskim, S. $142 \mathrm{f}$.

161 Am 3. V. 1922 wurde einer der Führer des estnischen Kommunismus, Viktor Kingisepp, von den estnischen Behörden verhaftet, wegen staatsfeindlicher Bestrebungen angeklagt, zum Tode verurteilt und hingerichtet. Zur Rolle Kingisepps in der kommunistischen Bewegung vgl. I. M. Saat, Bor'ba Viktora Kingiseppa protiv buržuaznogo nacionalizma v Éstonii, in: Istoričeskie Zapiski 45 (1954), S. 208-219. Die Erschießung Kingisepps rief bei der sowjetischen Regierung eine heftige Gegenreaktion hervor. Sie warf der estnischen Gesandtschaft in Moskau Spekulationsgeschäfte 
chen Spannungen führten am 22. August 1922 wieder zur Auflösung des „Ständigen Wirtschaftsbüros" $" 162$.

Es war bemerkenswert, daß Finnland und die baltischen Staaten in allen auf der Wirtschaftskonferenz berührten Fragen solidarisch aufgetreten waren und die Vertreter der Sowjetregierung diese Solidarität in keiner Weise erschwert, sondern im Gegenteil durch wohlwollende Aufnahme gemeinsamer baltisch-finnischer Einzelvorschläge eher erleichtert hatten ${ }^{163}$. Diese Haltung entsprach indes weitergehenden Zielen und Absichten der Sowjetregierung, die nicht ausschließlich auf ihr wirtschaftliches Interesse an einem reibungslosen Transitverkehr durch die baltischen Häfen zurückzuführen waren. Um Verbesserungen im Transitverkehr zu erreichen, hätte es der Einberufung einer gemeinsamen baltisch-finnisch-russischen Wirtschaftskonferenz zweifellos nicht bedurft. Die gewünschten Erleichterungen wären bei dem zunehmenden Interesse der baltischen Staaten und Finnlands, ihren Anteil am Transithandelsvolumen von und nach Rußland zu erhöhen, mit Sicherheit auch in bilateralen Verhandlungen zwischen der Sowjetregierung und den Regierungen Finnlands und der baltischen Staaten zu erreichen gewesen. Dadurch, daß die Sowjetregierung mit Finnland und den baltischen Republiken bewußt gemeinsam verhandelte, konnte sie die wirtschaftliche und politische Außenseiterstellung Polens in Nordosteuropa besonders wirkungsvoll zum Ausdruck bringen. Gerade aus diesem Grunde nahm die Sowjetregierung die Konferenz als einen großen politischen Erfolg gegenüber Polen in Anspruch.

Diese Einschätzung der Konferenzergebnisse wurde in einer Unterredung, die Ganeckij am 26. November 1921 mit dem Leiter der deutschen Vertretung in Moskau, Dr. Kurt Wiedenfeld, hatte, deutlich. Ganeckij, der inzwischen zum Mitglied des Kollegiums des sowjetischen Außenkommissariats ernannt worden war, betonte den

und Spionage vor und drohte mit der Verhaftung und Erschießung der estnischen Missionsmitglieder, falls nicht sämtliche in Estland verhaftete Kommunisten an Sowjetrußland ausgeliefert würden (Tel. Nr. 25 v. Hentig, Reval, 15. VI. 1922, PA, IV Rd, Pol 3, Est/Ru, Geheimakten, Bd. 1). Der estnische Ministerrat lehnte diese Forderung als mit der staatlichen Selbständigkeit unvereinbar ab (Ber. Nr. K. 13/22 v. Hentig, Reval, 16. VI. 1922, ebenda). Von ihrer Drohung nahm die Sowjetregierung Abstand, nachdem die estnische Regierung ihren bisherigen Gesandten in Moskau, Vares, abberufen und durch den Rechtsanwalt und früheren Außenminister Ado Birk ersetzt hatte, der eine Milderung der estnisch-sowjetischen Spannungen erreichen konnte (Ber. Nr. A 1673/22 v. Hentig, Reval, 21. VI. 1922, ebenda). Eine analoge Verschärfung war auch in den Beziehungen zwischen Lettland und Sowjetrußland zu beobachten. Während die lettische Regierung gegen die rege Tätigkeit des ehemaligen Chefs der lettischen Sowjetregierung von 1919, Stučka, bei der sowjetischen Regierung mit der Begründung Protest erhob, dessen in Moskau ausgeübte Tätigkeit sei auf die Vernichtung des bestehenden Lettland gerichtet (Aufzeichnung des AA unter Journal-Nr. IVa Rd 2960 vom 13. X. 1922 „Verhältnis der Randstaaten zu Rußland“, PA, IV Rd, Pol 3, Rd/Ru, Bd.. 2), beschuldigte die sowjetrussische Regierung im August 1922 den lettischen Militärattaché in Moskau, Oberst Bach, der Spionagetätigkeit und im September 1922 Mitglieder des lettischen Roten Kreuzes in Moskau illegaler Spekulations- und Schmuggelgeschäfte.

162 DVP IV, S. 793 f., Anm. 86.

163 Ber. Ko Nr. 249 v. Rudolph, Riga, 8. XI. 1921, PA, IV Rd, Wi 7, Bd. 1. 
immer stärkeren Wunsch der polnischen Regierung, sich ebenfalls möglichst stark an dem wachsenden Transitverkehr zwischen Deutschland und Rußland zu beteiligen. Durch die Rigaer Wirtschaftskonferenz aber, an der Polen bekanntlich nicht teilgenommen habe, sei die polnische Regierung ,auf die große Gefahr aufmerksam geworden, die ihr auf diesem Gebiet drohe“. Nicht zuletzt aus diesem Grunde äußerte Ganeckij die Gewißheit, daß „schon in allernächster Zeit ín Polen eine vollständige Änderung der bisher dort eingehaltenen politischen Richtung zu erwarten sei“ ${ }^{\text {“164. Den }}$ Äußerungen und Hinweisen Ganeckijs ist zu entnehmen, welche politischen Zielsetzungen die Sowjetregierung mit ihrer baltischen Politik gegenüber Polen verband. Über den Ausbau und die Intensivierung des Transithandels mit den baltischen Staaten suchte sie beharrlich den politischen Einfluß Polens im Baltikum einzudämmen, um dadurch der bisherigen polnischen Randstaatenpolitik die Grundlage zu entziehen. Von einer Zurückdrängung polnischer Einflüsse im Baltikum versprach sich die Sowjetregierung darüber hinaus dann auch Rückwirkungen auf die polnische Regierungspolitik selbst. Die Erfolglosigkeit der polnischen Randstaatenpolitik sollte eine Stärkung der Nationaldemokratie in Polen nach sich ziehen, von der sie wußte, daß diese den vom Belvedere verfolgten Plänen, einen gegen Sowjetrußland gerichteten polnisch-baltisch-finnischen Staatenbund zustandezubringen, mit Ablehnung gegenüberstand. Die wachsende Einsicht der polnischen Öffentlichkeit, daß die bisherige baltische Politik der Regierung auch die eigenen Hoffnungen auf eine Vermittlerrolle im europäisch-russischen Transithandel vermindert habe, würde wiederum der Nationaldemokratie jene innenpolitische Unterstützung sichern, die sie in ihrer Auseinandersetzung mit der Politik des Belvedere benötigte. Hieraus würde sich sehr bald eine grundsätzliche Änderung der sowjetfeindlichen Politik Polens auch im Baltikum ergeben. Für die Absichten und Ziele der sowjetischen Politik gegenüber Polen, die sich in diesen Gedankengängen bewegten, suchte Ganeckij sich schließlich auch deutscher Unterstützung zu vergewissern. Mit Nachdruck machte er Wiedenfeld in der erwähnten Unterredung auf die Erleichterungen im Transithandelsverkehr durch die baltischen Staaten aufmerksam und wies darauf hin, „daß Deutschland sich nicht die Gelegenheit entgehen lassen sollte, von den Randstaaten her Rußland zu bearbeiten" $" 165$.

Hatte die Sowjetregierung bereits die ernsten Befürchtungen der polnischen Nationaldemokratie vor einer Gefährdung des Rigaer Friedensvertrages geschickt auszunutzen verstanden und war es ihr nicht zuletzt deshalb gelungen, die von ihr geforderte Ausweisung der antisowjetischen Emigrantenführer aus Polen durchzusetzen ${ }^{166}$, so erwiesen sich auch die dargelegten Absichten und Überlegungen ihrer baltischen Politik gegenüber Polen als durchaus begründet. In der Tat ließ sich die Reaktion der Nationaldemokratie auf die an Polen vorbeigehenden Transithandelsvereinbarungen

164 Ber. Tgb. Nr. K/28 v. Wiedenfeld, Moskau, 28. XI. 1921, PA, IV Ru, Pol 2, Ru/Dt, Bd. 6, B1. 082'.

165 Ebenda, BL. 083.Vgl. auch Tel. Nr. 136 v. Wiedenfeld, Moskau, 28. XI. 1921, PA, IV Ru, Handel 11, Ru/Dt, Bd. 4.

166 Vgl. S. 80. 
zwischen Sowjetrußland und den baltischen Staaten alsbald in Angriffen ihrer Presseorgane auf die Regierungspolitik ablesen. Sie warf der Regierung unverzeihliche Passivität in der Transitfrage vor und beschuldigte sie in diesem Zusammenhang, vitale Interessen Polens zu schädigen. Verantwortlich für diese Lage machte die Nationaldemokratie jetzt eindeutig die antirussische Politik des Belvedere, während sie noch im September 1921 vornehmlich der Außenpolitik der lettischen Regierung den Vorwurf gemacht hatte, durch die Steigerung ihres Handels-und Transitverkehrs mit Sowjetrußland polenfeindliche Pläne zu verfolgen ${ }^{167}$. „Es hätte scheinen können, daß der Rigaer Friedensvertrag endlich ein Wendepunkt in den bisherigen Verhältnissen sein werde“, klagte der Leitartikel des nationaldemokratischen „Kurjer Poznański“ (Nr. 293) vom 22. Dezember 1921, um dann mit Entrüstung fortzufahren: „Indes trieb die polnische Politik ein zweideutiges und unreifes Spiel, in dem die unrealen Träume einer Weltherrschaft die Hauptrolle spielten und in dem es an irgendeiner nüchternen Vertiefung der wirklichen geschichtlichen Richtlinien absolut mangelte“. Besonders bezeichnend für die politische Grundeinstellung des nationaldemokratischen Blattes in dieser Frage war dabei, daß es der Politik des Belvedere zugleich eine Begünstigung deutscher Absichten gegen Polen zu unterstellen versuchte. „Unsere Politik gegenüber Rußland“, wurde in dem Leitartikel betont, „bewegte sich bisher deutlich auf der Linie der deutschen Intentionen, indem sie zwischen beiden Ländern eine stickige und unfreundliche Atmosphäre schuf". Dies habe nicht nur die Möglichkeiten künftiger Handelsbeziehungen zu Rußland erschwert, sondern eben auch dazu geführt, daß der bestehende Außenhandel Rußlands sich ausschließlich auf dem Seewege, mithin durch die baltischen Staaten vollziehe. Die Ausführungen wurden mit der kategorischen Forderung beendet, die polnische Regierung müsse endlich eine Änderung dieser Polen schädigenden Politik herbeiführen und eigene Handelsbeziehungen zu Rußland anknüpfen.

Das Belvedere glaubte zunächst, sich diesen Forderungen entziehen zu können, mußte jedoch bald erkennen, daß seine politischen Bemühungen, ein polnisch-baltisches Randstaatenbündnis gegen Sowjetrußland zustandezubringen, gescheitert waren und auch in absehbarer Zeit kaum Aussicht auf Erfolg haben würden. Insbesondere waren auch die Anregungen der diplomatischen Vertreter Polens in Lettland und Estland, der antipolnischen Entwicklung in der Randstaatenfrage mit einer Steigerung polnischer Exporte in diese Länder entgegenzuwirken ${ }^{168}$, nicht zu verwirklichen. Einer Erhöhung der Warenausfuhr Polens nach Lettland und Estland standen schwierige Verkehrsprobleme im Wege. Vor allem das Transitverbot für polnische Waren durch litauisches Staatsgebiet - eine Folge des polnisch-litauischen Konfliktes um das Wilnagebiet - mußte den Transport polnischer Exporterzeugnisse nach Lettland und Estland erheblich erschweren, da hierdurch nicht nur der Schiffstransport auf der Memel ${ }^{169}$, sondern auch die wichtige Eisenbahnverbindung über die Strecke Wilna-

167 Vgl. oben, S. 128.

168 Skrzypek, Związek bałtycki, S. 133.

169 Vgl. hierzu Andrzej Skrzypek, Zagadnienie Niemna (1918-1928), in: Z dziejów 5 (1969), S. 149-155. 
Kowno-Mitau-Riga blockiert war. Als Ausweichmöglichkeit auf dem Landwege bot sich der umständlichere und kostspieligere Transportweg auf der Eisenbahnstrecke Wilna-Dünaburg-Riga an. Der Frachtverkehr auf dieser Umgehungsstrecke war allerdings wegen der Kriegsschäden an der Eisenbahnbrücke über die Düna, die erst im Frühjahr 1922 beseitigt werden konnten, noch weitgehend eingeschränkt ${ }^{170}$.

Selbst ohne diese Behinderungen aber war sehr bald kaum eine wesentliche Erhöhung der Exporte Polens nach Lettland und Estland zu erwarten. Der in der Nachkriegszeit außerordentlich fühlbare Mangel an flüssigem Kapital ${ }^{171}$ machte es der polnischen Exportwirtschaft unmöglich, estnischen und lettischen Kaufleuten langfristige Kredite zu günstigen Bedingungen einzuräumen. Hinzu kam, daß die polnische Wirtschaft gerade im Herbst und Winter 1921 unter einer sich in raschem Tempo entwickelnden Industriekrisis litt ${ }^{172}$, die zusätzlich die Exportmöglichkeiten Polens sehr stark einschränkte oder sogar völlig unterband ${ }^{173}$. Im Herbst 1921 bestanden weder mit Lettland noch mit Estland handelsvertragliche Beziehungen. Der bestehende Wirtschaftsverkehr zwischen Polen und diesen Ländern beschränkte sich auf den Handel mit Zucker und Ölprodukten ${ }^{174}$. Obwohl Polen in den folgenden Jahren auch Kohle, Salz, Textilien und Landmaschinen in diese Länder lieferte und seinerseits von dort Flachs, Holz, Leder und Papier bezog ${ }^{175}$, blieb das Handelsvolumen minimal und erreichte weder für Polen noch für Lettland oder Estland volkswirtschaftliche Bedeutung ${ }^{176}$. Die Handelsbeziehungen zwischen Polen einerseits und Lettland bzw. Estland andererseits bildeten somit kein Element, das auch ihre politische Zusammenarbeit hätte erleichtern oder fördern können. Ihre gleichen Außenhandelsrichtungen nach Mittel- und Westeuropa ${ }^{177}$ sowie ihre ähnliche Außenhandelsstruktur führten im Gegenteil eher dazu, daß sie sich auf ausländischen Märkten als Handelskonkurrenten begegneten und ihren Absatz gegenseitig behinderten ${ }^{178}$. Unter diesen Umständen

170 Skrzypek, Związek bałtycki, S. 121 f., 133.

171 Zbigniew Landau/Jerzy Tomaszewski, Zarys historii gospodarczej Polski 1918-1939, Warschau 1960, S. $55 \mathrm{ff}$.

$172 \mathrm{Zu}$ den finanz- und währungspolitischen Ursachen der Industriekrise in Polen im Herbst und Winter 1921 vgl. Gospodarka Polski międzywojennej, Bd. 1 (1918-1923), Warschau 1967, S. $268 \mathrm{f}$.

173 Ber. der deutschen Gesandtschaft Warschau v. 26. XI. 1921, PA, Büro RM, 69, Informatorische Aufzeichnungen (Nr. 47 v. 10. XII. 1921), Bd. 1. Diesem Bericht zufolge waren folgende für die polnische Exportwirtschaft wichtige Industriezweige von der Krise betroffen: die Textilindustrie, die Metallindustrie, die Zementindustrie, die Holzindustrie und die Gerbindustrie.

174 Skrzypek, Związek baltycki, S. 134.

175 Wojciech Stopczyk, Handel międzynarodowy na Baltyku, Toruń 1928, S. 20.

176 Volkswirtschaftlich ebensowenig bedeutsam war auch der Handel Polens mit Finnland und Litauen.

177 Hauptabnehmer estnischer und lettischer Erzeugnisse war Großbritannien, gefolgt von Deutschland. Die Masse der polnischen Exportgüter ging nach Deutschland. Großbritannien, die Tschechoslowakei und Österreich bildeten nach Deutschland die wichtigsten Absatzgebiete für polnische Exporte.

178 Die polnische Ausfuhr der Jahre 1921-1929 bestand im Dưrchschnitt zu etwa 20 Prozent aus landwirtschaftlichen Erzeugnissen (Getreide, Zucker) und zu etwa 40 Prozent aus Holz, Roh- und 
war die Absicht des Belvederelagers, dem polnischen Einfluß auf die baltischen Staaten auch auf handelspolitischem Gebiet stärkere Geltung zu verschaffen, nichts anderes als politisches Wunschdenken. Gerade in der baltischen Politik des Belvedere kam das Mißverhältnis zwischen seinem politischen Anspruch und den tatsächlichen Möglichkeiten Polens deutlich zum Ausdruck. Seinen weitreichenden Bündnisbestrebungen im Baltikum fehlte eine entsprechende wirtschaftliche Grundlage völlig. Auf politischem und militärischem Gebiet aber war und blieb Polen vornehmlich dann den baltischen Randstaaten ein wichtiger und erwünschter Bündnispartner, wenn diese sich von Sowjetrußland bedroht glaubten. Insofern waren gespannte Beziehungen zwischen Sowjetrußland und den baltischen Staaten geradezu eine wesentliche Voraussetzung für die Bündnispläne des Belvedere im Baltikum. Jede Entspannung im Verhältnis Sowjetrußlands zu den baltischen Staaten war somit auch umgekehrt mit einer gleichzeitigen Minderung des polnischen Einflusses im baltischen Raum verbunden.

Das offenkundige Scheitern der antirussischen Randstaatenpläne des Belvedere bildete gegen Ende 1921 ein weiteres Element für die innenpolitische Stärkung der polnischen Nationaldemokratie, deren Forderungen nach einer außenpolitischen Entspannung gegenüber Sowjetrußland sich nunmehr stärker durchzusetzen begannen. Ein wesentlicher Bestandteil ihrer Bemühungen um eine polnisch-sowjetische Entspannung war nach ihrer Auffassung die Herstellung beiderseitiger handelsvertraglicher Beziehungen. Es sollte sich indes herausstellen, daß entsprechende Vereinbarungen mit Sowjetrußland weniger von ihrem Entspannungswillen abhingen, als weit stärker mit den politischen und wirtschaftlichen Interessen sowohl Sowjetrußlands als auch Deutschlands verknüpft waren.

Halbstoffen der Hütten- und Textilindustrie. Vgl. Kürbs, S. 82f.; Stopczyk, S. 56; Gospodarka Polski międzywojennej, Bd. 1 (1918-1923), S. 344, Bd. 2 (1924-1929), S. 294. 